\title{
The Intergenerational Transmission of Family-Income Advantages in the United States
}

\author{
Pablo A. Mitnik, ${ }^{a}$ Victoria Bryant, ${ }^{b}$ Michael Weber ${ }^{b}$
}

a) Stanford University; b) Internal Revenue Service

\begin{abstract}
Estimates of economic persistence and mobility in the United States, as measured by the intergenerational elasticity (IGE), cover a very wide range. Nevertheless, careful analyses of the evidence suggested until recently that as much as half, and possibly more, of economic advantages are passed on from parents to children. This "dominant hypothesis" was seriously challenged by the first-ever study of family-income mobility based on tax data (Chetty et al. 2014), which provided estimates of family-income IGEs indicating that only one-third of economic advantages are transmitted across generations and claimed that previous highly influential IGE estimates were upward biased. Using a different tax-based data set, this article provides estimates of family-income IGEs that strongly support the dominant hypothesis. The article also carries out a one-to-one comparison between IGEs estimated with the two tax-based data sets and shows that Chetty et al's estimates were driven downward by a combination of attenuation, life-cycle, selection, and functional-form biases. Lastly, the article determines the exact relationship between parental income inequality, economic persistence, and inequality of opportunity for income. This leads to the conclusion that, in the United States, at least half of income inequality among parents is transformed into inequality of opportunity among their children.
\end{abstract}

Keywords: intergenerational transmission of economic advantages; economic mobility; intergenerational elasticity; income inequality; equality of opportunity; administrative data

Citation: Mitnik, Pablo A., Victoria Bryant, and Michael Weber. 2019. "The Intergenerational Transmission of Family-Income Advantages in the United States." Sociological Science 6: 380415.

Received: February 4, 2019

Accepted: March 29, 2019

Published: May 15, 2019

Editor(s): Kim Weeden

Dol: $10.15195 / \mathrm{v} 6 . \mathrm{a} 15$

Copyright: (C) 2019 The Author(s). This open-access article has been published under a Creative Commons Attribution License, which allows unrestricted use, distribution and reproduction, in any form, as long as the original author and source have been credited. (C) (i)
$\Gamma^{O}$ what extent are economic advantages passed on from parents to children in 1 the United States? What share of economic inequality among families persists from one generation to the next? How much economic mobility across generations is there? How far is the country from achieving the normative ideal of equality of opportunity in the economic realm? The intergenerational elasticity has been, by a large margin, the measure most often employed to answer these crucial questions. ${ }^{1}$ The IGE of men's earnings has been extensively estimated, in most cases with survey data (see reviews by Solon 1999; Corak 2006; and Mitnik et al. 2018) but also with information from the Social Security Administration (Mazumder 2005; Dahl and DeLeire 2008). The IGE of family income has also been estimated in the United States but less often than that of earnings and, until very recently, exclusively with survey data. ${ }^{2}$

The available IGE estimates cover a very wide range. Nevertheless, careful analyses of the evidence accumulated over decades of research, which were very strongly influenced by the administrative-data results reported by Mazumder (2005), led over time to the tentative conclusion that U.S. income and (men's) earnings IGEs are not smaller than 0.5. For instance, in his most recent appraisal of the literature, Solon (2008:4) contended that once all downward biases in the estimation of the IGE are considered, "it becomes plausible that the intergenerational elasticity in 
the United States may well be as large as 0.5 or 0.6." Similarly, Black and Devereux (2011:1495-6) recently wrote in the Handbook of Labor Economics that "a reasonable guess is an IGE [in the United States] of about 0.5 to 0.6." An IGE in this range entails that at least half of economic advantages are passed on from one generation to the next. In turn, this has often been interpreted as loosely suggesting a very high level of inequality of opportunity in the country, both in absolute terms and compared to most other highly developed countries (for cross-country comparisons of IGEs see, e.g., Jäntti et al. 2006; Corak 2013). We will refer to the view that at least half of economic advantages persist across generations and that this is a very high level of persistence as the "dominant hypothesis."

The publication, in a top economics journal, of the first-ever study of familyincome mobility in the United States based on tax data (Chetty et al. 2014) has cast serious doubts on the dominant hypothesis. In their highly influential article, Chetty et al. (2014) argued that Mazumder's (2005) approach to dealing with missing parental data had led to upward-biased IGE estimates. ${ }^{3}$ In addition, although Chetty et al. (2014) found out that their IGE estimates were nonrobust to the treatment of children who did not file taxes as adults, they nevertheless reported a preferred estimate of the family-income IGE that is as low as 0.34 (for men and women pooled). ${ }^{4}$ This estimate indicates that about one-third, rather than at least half, of economic advantages are passed on from parents to children. It also indicates much less economic persistence than what has been generally assumed to be the case since Mazumder's (2005) publication; although economic persistence in the United States has been deemed, for some time now, to be the highest or close to the highest among highly developed countries, an IGE of about 0.34 would mean that this persistence is in fact very close to the average persistence across those countries. ${ }^{5}$ As the survey data employed in mobility research are affected by a long list of problems and limitations that reduce the confidence we can place on the resulting IGE estimates (Schoeni and Wiemers 2015; Mitnik et al. 2018:10-11), Chetty et al.'s (2014) lower-end estimate of the income IGE with high-quality tax data, together with their criticism of Mazumder's (2005) administrative-data results, have seriously undermined the epistemic status of the dominant hypothesis. ${ }^{6}$

IGEs are defined in terms of long-run income variables. However, as it has nearly always been the case in the literature, Chetty et al. (2014) used short-run proxy variables to estimate them. Mobility scholars have long emphasized that many things may go wrong in this context (e.g., Mazumder 2005; Haider and Solon 2006; Mitnik and Grusky 2017), so it is very important to determine whether Chetty et al.'s IGE estimates are on the mark. If the share of economic advantages transmitted across generations were really close to one-third, that would mean that the dominant hypothesis is simply mistaken.

In this article, we contend that nothing of the sort is the case. Relying on several samples from the Statistics of Income Mobility (SOI-M) Panel (Mitnik et al. 2015), a different tax-based data set than that used by Chetty et al. (2014), we provide IGE estimates that strongly support the view that at least half of economic advantages are transmitted from parents to children and show that Chetty et al.'s estimates were driven downward by a combination of attenuation, life-cycle, selection, and functional-form biases. By supplementing Chetty et al.'s (2014) estimates with 
additional IGE estimates based on aggregate tax-based statistics they have made publicly available, we are able to carry out a one-to-one comparison between IGEs estimated with our and Chetty et al.'s (2014) data. This comparison shows that estimates based on the two tax-based data sets (and associated methodological decisions) are systematically and markedly different and imply quite contrasting assessments of the extent to which inequalities among families are transmitted across generations. Moreover, the comparison is consistent with our contention that the estimates reported, as well as those based on the data employed, by Chetty et al. (2014) are affected by the aforementioned biases. Strong evidence that this is the case is then furnished by (1) using the SOI-M Panel to generate a data set replicating the key "bias-generating features" of Chetty et al.'s sample and methodological decisions, and showing that the estimates move in the expected direction in all cases and are quite close to Chetty et al.'s after all biases are introduced, and (2) computing Shapley decompositions (Shorrocks 2013) to quantify the specific contribution of each bias to the differences in results.

In addition, in this article, we provide the first formal account of the relationship between cross-sectional inequality, economic persistence, and inequality of opportunity. ${ }^{7}$ This allows us to advance a novel and compelling justification for the interpretation of an IGE as the share of economic advantages or inequality transmitted across generations (or "share interpretation" of the IGE). It also allows us to make the relationship between the transmission of economic advantages and inequality of opportunity transparent, which (1) leads to the conclusion that, in the United States, at least half of income inequality among parents is transformed into inequality of opportunity for income among their children and (2) provides a clear rationale for the notion that there is a very high level of inequality of opportunity in the country compared to most other highly developed countries.

Our article is most closely related to Mazumder (2016) and Mitnik et al. (2018). Like us, Mazumder (2016) criticizes Chetty et al.'s (2014) IGE estimates. However, he focuses exclusively on one of the four IGEs we examine (the constant IGE conventionally estimated in the literature), only considers two of the four biases we discuss (the life-cycle and attenuation biases), and relies on survey data affected by the problems and limitations mentioned earlier and very different, both in nature and in terms of the period they cover, from the tax data used by Chetty et al. (2014). In contrast, we use a data set unaffected by those problems and limitations and built from data sources very similar to those used by Chetty et al. (2014), measure family income in a very similar way to theirs, and focus on a time period adjacent to the one they consider (2010 compared to 2011 and 2012). ${ }^{8}$ Our analyses here and Mitnik et al.'s (2018) are complementary. Both provide tax-based IGE estimates consistent with the dominant hypothesis and use the same sample for this purpose. However, we provide here family-income IGE estimates for men and women pooled rather than by gender (as Mitnik et al. [2018] do), which allows us to carry out a straightforward comparison with Chetty et al.'s (2014) estimates and with other estimates based on their data. More crucially, whereas Mitnik et al. (2018) focus exclusively on their preferred IGE concept, the IGE of expected income, here we pay equal attention to that IGE and to the IGE of the geometric mean of income; this makes direct comparisons with the large number of results reported in the 
literature, both for the United States and for other countries, possible (as we explain later, the latter IGE concept is what has been unwittingly estimated in the mobility literature). Equally important, whereas Mitnik et al. (2018) do not explain in any detail why their estimates and Chetty et al.'s (2014) estimates differ, accounting for why the latter and our estimates differ is one of our main goals. Lastly, Mitnik et al. (2018) do not offer any account of the relationship between cross-sectional inequality, IGEs, and inequality of opportunity; rely on the (less appealing) standard justification for the share interpretation of IGEs; and do not provide a rationale for the interpretation of high economic persistence in the United States in terms of inequality of opportunity, as we do here.

We lead off the article by introducing a generic notion of IGE, the four specific IGEs that are relevant for our arguments, and our account of the relationship between cross-sectional inequality, economic persistence, and inequality of opportunity. This is followed by a description of estimators and potential estimation biases and the strategies used to address the latter. Next, we introduce the data we use and explain why they can be expected to lead to better estimates than those obtained by Chetty et al. (2014). After that, we make our empirical case. The last section discusses our results and distills the article's main conclusions.

\section{Conditional Income Distributions, Intergenerational Curves, and Economic Persistence}

Questions about the transmission of economic advantages from parents to children, the persistence of inequality across generations, economic mobility, and inequality of opportunity may be expressed as questions about the distribution of children's income (as adults) conditional on their parents' income. If the conditional distribution of children's income does not vary across parental incomes, then no transmission of economic advantage or economic persistence exists and there is "perfect mobility" and full equality of opportunity. ${ }^{9}$ If, on the contrary, the children's conditional distributions become "better" as parental income increases, then advantages are passed on in some degree, economic status is a persistent property, mobility is imperfect, and there is inequality of opportunity. ${ }^{10}$

Therefore, a possible approach to answering questions about persistence and inequality of opportunity is to compare full conditional distributions across levels of parental income and assess how those distributions change as parental income increases (e.g., Lefranc, Pistolesi, and Trannoy 2009). Data constraints, however, make it difficult to estimate full conditional distributions with precision. Moreover, it is rather unwieldy to compare them even if they can be estimated. One way to deal with these two problems is to (1) summarize the information contained in full conditional distributions by using a measure of central tendency, for instance, the arithmetic mean or expectation; (2) specify and estimate an "intergenerational curve" relating the selected measure of central tendency of children's income to parental income; and (3) summarize the information in that curve in a way that is relevant for the questions at hand. 
Analyses based on IGEs carry out the last task by focusing on the slope of the intergenerational curve, with the curve being defined in log-log space rather than in the space spanned by the income variables. The focus on the slope may be motivated as follows: A fully flat intergenerational curve indicates no economic persistence or inequality of opportunity (at least in terms of the selected measure of central tendency of income), whereas an increasing curve indicates the opposite, so mobility scholars found it natural to think of steeper curves as indicating more economic persistence and less mobility. ${ }^{11}$ But why define the curve in log-log space? The reason is that, in log-log space, the slope has attractive properties that it doesn't have otherwise: It is invariant to proportional economic growth (i.e., economic growth that leads to proportional increases in all children's incomes), to changes in measurement units, and to changes in price levels (for related comments, see Mulligan 1997:25). These are important properties, among other things, because they make meaningful comparisons across countries and times possible.

So far, we have referred to "the" slope of the intergenerational curve in log-log space despite the fact that the slope may vary across levels of parental income. There is good evidence, however, that the curve is monotonically increasing (that is, it always increases when parental income increases), at least with the measures of central tendency relevant here (see Chetty et al.'s [2014] Online Appendix Fig. 1). Therefore, the intuition that a steeper slope indicates less economic mobility and more economic persistence is still valid as long as we switch our focus to the expected slope across values of parental income-or, equivalently, to the average slope of the curve, when this average is a weighted average with weights equal to the density of each parental income value. ${ }^{12}$ In fact, this notion also covers the case in which the slope of the intergenerational curve is constant in log-log space-that is, when the elasticity is constant-as in this case the average slope is of course equal to that constant slope.

The foregoing suggests a characterization of a generic IGE as the average slope of an intergenerational curve defined in log-log space, with the specific measure of central tendency employed in the curve giving rise to a specific IGE concept. Furthermore, actual IGE estimates also depend on the functional form posited for the relationship between children's and parental income in log-log space. It follows than an IGE is always an average point elasticity, across values of parental income, of a measure of central tendency of children's income with respect to parental income. Selecting a measure of central tendency and a functional form specifies a particular IGE.

\section{Intergenerational Elasticities, Share Interpretations, and Inequality of Opportunity}

The four specific IGEs that are relevant for the comparisons at the core of this article are obtained as indicated in Figure 1, in which the measures of central tendency considered are the expectation and the geometric mean and the functional forms are a straight line and an unknown smooth function. As the assumption of a straight line naturally leads to the estimation of parametric constant-elasticity 


\section{Shape of intergenerational curve in log-log space}

\begin{tabular}{|c|c|c|c|}
\hline & & Straight line & Smooth curve \\
\hline \multirow{2}{*}{$\begin{array}{l}\text { Measure } \\
\text { of central } \\
\text { tendency }\end{array}$} & $\begin{array}{l}\text { Geometric } \\
\text { mean }\end{array}$ & $\begin{array}{l}\text { Constant } \\
\text { IGE }_{g}\end{array}$ & $\begin{array}{c}\text { Nonparametric } \\
\mathrm{IGE}_{\mathrm{g}}\end{array}$ \\
\hline & Expectation & $\begin{array}{l}\text { Constant } \\
\text { IGE }_{\mathrm{e}}\end{array}$ & $\begin{array}{c}\text { Nonparametric } \\
\operatorname{IGE}_{\mathrm{e}}\end{array}$ \\
\hline
\end{tabular}

Figure 1: Four IGEs.

models, whereas the assumption of a smooth curve naturally leads to the estimation of nonparametric models, we will refer to the four IGEs as the constant $\mathrm{IGE}_{e}$, the constant $\mathrm{IGE}_{g}$, the nonparametric $\mathrm{IGE}_{e}$, and the nonparametric $\mathrm{IGE}_{g}$ of children's family income with respect to parental income (where the subscripts " $\mathrm{e}$ " and " $\mathrm{g}$ " distinguish between IGE concepts [i.e., the IGE of the expectation and the IGE of the geometric mean]).

Let's unpack these four IGEs, starting with the constant $\mathrm{IGE}_{g}$. Its use of the geometric mean as the measure of central tendency is the unintended-and, until very recently, unnoticed-result of the reliance on logarithmically transformed income variables to produce the elasticity estimates widely reported in the mobility literature (Mitnik and Grusky 2017). Indeed, the standard population regression function (PRF) posited by mobility scholars (e.g., Solon 1999) is:

$$
E(\ln Y \mid x)=\beta_{0}+\beta_{1} \ln x
$$

which may be written as

$$
\ln G M(Y \mid x)=\beta_{0}+\beta_{1} \ln x,
$$

where $Y$ is the children's long-run income, $X$ is long-run parental income, GM is the geometric mean operator, and $\beta_{1}$ is the income IGE the mobility literature 
has ubiquitously estimated (see Appendix B in the online supplement). ${ }^{13}$ This conventionally estimated elasticity has been widely misinterpreted: Although mobility scholars have assumed that they estimated the elasticity of the expectation of children's income, they in fact estimated, as Equation ( $\left.1^{\prime}\right)$ shows, the elasticity of the geometric mean of children's income. In other words, $\beta_{1}$ is the percentage differential in the geometric mean of children's long-run income with respect to a marginal percentage differential in parental long-run income.

Due to a host of conceptual and methodological problems, the constant $\mathrm{IGE}_{g}$ is not an attractive estimand; crucially, estimation of $\beta_{1}$ with the data that are in most cases available can be expected to be affected by a well-understood form of selection bias (Mitnik and Grusky 2017). As we will show later, this problem strikes with a vengeance if the data employed are tax data including a substantial share of nonfiling children, and these (or a large share of them) are dropped from the analysis. Despite its shortcomings, the constant $\mathrm{IGE}_{g}$ is the workhorse measure of mobility employed in the literature. For this reason, it is important to include it in our comparison.

Estimation of the constant $\mathrm{IGE}_{e}$ is based on the following PRF:

$$
\ln E(Y \mid x)=\alpha_{0}+\alpha_{1} \ln x
$$

where $\alpha_{1}$ is the percentage differential in the expectation of children's long-run income with respect to a marginal percentage differential in parental long-run income. Mitnik and Grusky (2017) have called for making this elasticity the workhorse intergenerational elasticity. They have shown that this elasticity is what mobility scholars assumed they were obtaining by estimating Equation 1 and that all interpretations incorrectly applied to $\beta_{1}$ are valid or approximately valid for $\alpha_{1}$.

A key such interpretation, which we strongly emphasize in this article, is the share interpretation, according to which an IGE measures the share of economic advantages or inequality transmitted across generations. This interpretation may be based on two different analyses-both for the $\mathrm{IGE}_{g}$ and for the $\mathrm{IGE}_{e}$-although only the analysis we present first has been previously considered in the literature (see, e.g., Mitnik and Grusky 2017). In the case of the $\mathrm{IGE}_{e}$, from Equation 2, it immediately follows that:

$$
\alpha_{1}=\frac{\ln E\left(Y \mid x_{2}\right)-\ln E\left(Y \mid x_{1}\right)}{\ln x_{2}-\ln x_{1}},
$$

where we assume, without any loss of generality, that $x_{2}>x_{1}$. As a difference in logarithms approximates well a percentage difference as long as the latter is fairly small, it is the case that

$$
\alpha_{1} \approx \frac{E\left(Y \mid x_{2}\right)-E\left(Y \mid x_{1}\right)}{E\left(Y \mid x_{1}\right)}\left[\frac{x_{2}-x_{1}}{x_{1}}\right]^{-1}
$$

as long as the ratio between $x_{2}$ and $x_{1}$ is not much larger than 1 . That is, under the conditions just specified, $\alpha_{1}$ is approximately equal to the ratio between the proportional difference in the expected income of children and the proportional difference in the income of their parents. Interpreting $\alpha_{1}$ as the share of advantages 
or inequality that is transmitted across generations requires (1) invoking a local notion of advantage or inequality - that is, advantage or inequality between families that are close in the income distribution-and (2) measuring this advantage or inequality by the proportional difference between those families' incomes.

The second, novel, analysis uses a regular (i.e., global) measure of income inequality and therefore maps more smoothly into the notion that income inequality is transmitted across generations and that IGEs measure the extent to which that is the case. Crucially, this analysis also makes the relationship between IGEs and inequality of opportunity fully transparent.

Denoting the standard deviation operator by SD, it follows from Equation 2 (see Appendix $C$ in the online supplement) that:

$$
\alpha_{1}=\frac{S D(\ln E(Y \mid X))}{S D(\ln X)} .
$$

The numerator on the right-hand side of Equation 5 is the standard deviation of the logarithm of children's expected adult income across values of parental income, whereas the denominator is the standard deviation of the logarithm of parental income. Both the numerator and denominator are then the standard deviation of the logarithm of an income variable, which is a commonly used measure of income inequality (e.g., Bourguignon and Morrisson 2002). ${ }^{14}$ This means that the constant $\mathrm{IGE}_{e}$ is equal to a ratio of inequality measures.

Explaining the significance of the inequality measure in the numerator of Equation 5 requires a brief detour into the burgeoning empirical literature on inequality of opportunity (for reviews, see Ramos and Van de gaer 2015; Ferreyra and Peragine 2016; Roemer and Trannoy 2016). In terms of philosophical foundations, this literature has mostly developed following the "luck egalitarian" understanding of inequality of opportunity, in which only inequalities for which individuals cannot be held responsible are deemed unjust (e.g., Arneson 1989; Cohen 1989; Roemer 1998; for a survey, see Arneson 2011). Empirically, most analyses have implemented a particular variant of what is known as the "ex-ante approach" for conceptualizing and studying inequality of opportunity. As applied to the case of interest here-that is, inequality in opportunities for income (e.g., Checchi, Peragine, and Serlenga 2010; Ferreyra and Gignoux 2011; Brunori, Ferreira, and Peragine 2013) - that variant of the ex-ante approach can be schematically summarized as follows: (1) "Circumstances" are all the things beyond people's control (and for which, therefore, they cannot be held responsible), (2) "types" are groups of individuals who share the same circumstances, (3) the individuals belonging to a type all share a common "opportunity set" (i.e., a set of income prospects), (4) the value of each opportunity set is measured by the mean of the realized incomes of those belonging to the type, and (5) inequality of opportunity is measured by the inequality in opportunity-set values across individuals. ${ }^{15}$

Although people's circumstances are most certainly not defined exclusively by their parents' income, types defined in terms of parental income do constitute a first approximation to types defined in terms of all circumstances. Therefore, the foregoing discussion suggests that $S D(\ln E(Y \mid X))$ provides a rough approximation to a society's inequality of opportunity for income. Strictly speaking, however, 
inequality of opportunity measured with respect to any incomplete set of circumstances (e.g., parental income alone) provides a lower bound to total inequality of opportunity (for a formal proof, see Section 3 of Ferreyra and Gignoux 2011). At the same time, in practice, inequality of opportunity is always measured with respect to an incomplete set of circumstances. This suggests an exact way of interpreting Equation 5 based on the notion of "inequality of opportunity modulo $W$," where "modulo $W$ " is stipulated to mean "computed with respect to the incomplete set of circumstances W." Indeed, relying on this notion of inequality of opportunitywhich, arguably, is a notion already implicitly used in the empirical literature on inequality of opportunity - the constant $\mathrm{IGE}_{e}$ (i.e., $\alpha_{1}$ ) is exactly equal to the ratio between (1) the inequality in children's opportunities for income modulo parental income (or inequality of opportunity, for short) and (2) the inequality in parental income itself.

Equations 4 and 5 both underlie the share interpretation of the constant $\mathrm{IGE}_{e}$, according to which the latter measures the share of income inequality or advantages among families that is passed on to (the expected incomes of) their children. Analogous analyses can be provided for the constant $\mathrm{IGE}_{g}$ by simply replacing expectations with geometric means (and $\alpha_{1}$ with $\beta_{1}$ ) in Equations 3,4 , and 5, which leads to the conclusion that the constant $\mathrm{IGE}_{g}$ measures the share of income inequality or advantages among families that is passed on to (the geometric mean of the incomes of) their children. Here, for the connection to inequality of opportunity to be maintained, opportunity sets need to be indexed not by the children's expected incomes conditional on parental income-as the empirical literature on inequality of opportunity has typically proposed-but by the corresponding conditional geometric means. ${ }^{16}$

Equation 5 and its counterpart for the $\mathrm{IGE}_{g}$ make transparently clear that a constant IGE does not measure inequality of opportunity per se, as the latter is equal to the inequality among parents multiplied by the IGE. In other words, an IGE measures the rate at which parental income inequality gets transformed into inequality of opportunity. However, because countries with larger IGEs also tend to exhibit more cross-sectional income inequality, economic persistence and inequality of opportunity are highly (but far from perfectly) correlated (Brunori et al. 2013). ${ }^{17}$

The assumption of a constant IGE has been adopted more as a matter of necessity (given the small samples available) than by virtue of any strong prior that it in fact holds. Unfortunately, if it doesn't hold, then estimates obtained under the constant-elasticity assumption are affected by functional-form bias (Bratsberg et al. 2007). To address this potential bias, Mitnik et al. (2018) proposed estimating the nonparametric $\mathrm{IGE}_{e}$. Here, the assumption that the curve relating children's expected income to their parental income is a straight line in log-log space is replaced by the following, much weaker, assumption:

$$
\ln \mathrm{E}(Y \mid x)=\mathrm{F}(\ln \mathrm{x}),
$$

where $F$ is an unknown smooth function. The resulting persistence measure has a share interpretation that generalizes the first one we discussed in the case of the constant $\mathrm{IGE}_{e}$. Assume that pairs of families whose incomes do not differ much in percentage terms are randomly drawn from the parental income distribution. 
Then, the nonparametric $\mathrm{IGE}_{e}$ approximates the expected share of inequality or advantages passed on to their children across all possible random draws. If the constant-elasticity assumption holds, then this interpretation also applies, trivially, to the constant $\mathrm{IGE}_{e}$ (see Equation [4]). In addition, we show in Appendix C in the online supplement that the nonparametric $\mathrm{IGE}_{e}$ also provides an approximation to the ratio between the global measures of inequality of opportunity and of parental income we introduced above (the quantity on the right-hand side of Equation [5]).

The last IGE is the nonparametric $\mathrm{IGE}_{g}$. Its definition and interpretation are analogous to those of the nonparametric $\mathrm{IGE}_{e}$ but substituting the conditional geometric mean of children's income for their conditional expectation and, accordingly, replacing Equation 6 with:

$$
\ln G M(\mathrm{Y} \mid \mathrm{x})=\mathrm{E}(\ln Y \mid x)=\mathrm{G}(\ln x),
$$

where $G$ is an unknown smooth function. A share interpretation analogous to that advanced in the case of the nonparametric $\mathrm{IGE}_{e}$ is of course available.

Before finishing this section, it seems important to stress what the ontological status of IGEs is. Sometimes, causal language slips into discussions of IGE estimates, and there obviously are causal processes underlying them, but the IGEs themselves are not causal parameters. Rather, these are all descriptive measures-akin to, for instance, the Gini coefficient. Although they are all-important measures, it is simply a category mistake to interpret them as measures of the causal effects of parental income. This in turn entails that the characterization of the $\mathrm{IGE}_{g}$ and the $\mathrm{IGE}_{e}$ as "person-weighted" and "dollar-weighted" elasticities (Chetty et al. 2014:1574 and Online Appendix C), respectively, according to which the $\mathrm{IGE}_{g}$ is a simple average of person-level behavioral elasticities, whereas the $\mathrm{IGE}_{e}$ is a weighted average of the same elasticities that gives more weight to people with more income, is invalid (for details, see Mitnik 2017c).

\section{Estimators and Potential Biases Due to the Use of Short-Run Income Measures}

As measures of long-run (e.g., lifetime) income are almost never available, estimation of IGEs is typically carried out by substituting short-run proxy variables for the long-run variables of interest. All empirical estimates we discuss in later sections were obtained by (1) replacing the long-run income of children $(Y)$ by an annual family-income measure pertaining to when the children were in their 30s, or by an average of such annual measures over two years, and (2) replacing the long-run income of parents $(X)$ by their average income over several years, pertaining to when the children were young (we provide details on the exact income measures used later). Below, when we refer to Equations 1, 2, 6, and 7, we are referring to versions of these equations with the short-run proxy variables substituted for their long-run counterparts. We first introduce the relevant estimators and then discuss the potential biases that the substitution of short-run proxy variables may generate. 


\section{Estimators}

The estimators employed to estimate the four IGEs in Figure 1 are depicted in Figure 2. We briefly describe them here. A detailed discussion of these estimators as well as other estimation issues can be found in Appendix D in the online supplement.

Following the most common approach in the mobility literature, all estimates of the constant $\mathrm{IGE}_{g}$ that we discuss are the result of estimating the PRF of Equation 1 by ordinary least squares (OLS); that is, they were obtained with the OLS log-log estimator. In contrast, the estimates of the constant $\mathrm{IGE}_{e}$ rely on two different approaches. The new estimates we present here were obtained by estimating Equation 2 with the Poisson Pseudo-Maximum Likelihood (PPML) estimator (Santos Silva and Tenreyro 2006). The estimate of the constant $\mathrm{IGE}_{e}$ reported by Chetty et al. (2014) that we will discuss is based on a two-step estimator of the same equation. In the first step, nonparametric estimates of $\ln E(Y \mid \ln x)$ are generated; in the second step, an estimate of $\alpha_{1}$ is obtained by running an OLS regression of the estimates of $\ln E(Y \mid \ln x)$ on the corresponding $\ln x$ values.

The estimators of the nonparametric IGEs are two-step estimators in all cases: The first step produces nonparametric estimates of a number of points in the relevant intergenerational curve (i.e., the curve defined by either Equation [6] or Equation [7]), whereas the second step estimates the average slope of the curve through a numerical approximation based on the estimated points. Across data sets, the estimators only differ on the nonparametric approach used to estimate the points of the intergenerational curves and on the number of points that are estimated and employed in the numerical approximations.

\section{Potential Biases}

When estimating the constant $\mathrm{IGE}_{g}$, substituting short-run proxy measures for the long-run measures of interest opens the door to three biases, two of which have been extensively discussed in the mobility literature. First, measurement error produces substantial attenuation bias if annual measures of parental income, or other measures based on a few years of information, are used to estimate Equation 1 by OLS (e.g., Solon 1999; Mazumder 2005). ${ }^{18}$ Second, as income-age profiles differ across economic origins, life-cycle biases result from using proxy measures taken when parents or children are too young or too old to represent lifetime differences well (e.g., Black and Devereux 2011). A formal joint analysis of these two biases is provided by Haider and Solon's (2006) generalized error-in-variables model. It follows from this model that using measures of economic status pertaining to specific ages should eliminate the bulk of the life-cycle biases; in addition, the evidence available suggests that using parents' and children's information close to age 40 is the best approach (Mazumder 2001; Haider and Solon 2006; Böhlmark and Lindquist 2006; Nybom and Stuhler 2016; Mitnik 2017b). To address the problem of attenuation bias, Haider and Solon's (2006) model—and many analyses predating it (e.g., Solon 1992)—suggests using parents' average income over several years as the measure of parental income. There is strong evidence that the bias can

be substantially reduced this way if the average is computed over enough years, 


\begin{tabular}{|c|c|c|}
\hline \multirow[t]{2}{*}{ IGE } & \multicolumn{2}{|c|}{ Data } \\
\hline & Chetty et al. (2014) & SOI-M Panel \\
\hline Constant IGE $\mathrm{g}_{\mathrm{g}}$ & $\begin{array}{l}\text { OLS log-log estimator } \\
\text { Estimation of Equation [1] by Ordinary Least Squares }\end{array}$ & $\begin{array}{l}\text { OLS log-log estimator } \\
\text { Estimation of Equation [1] by Ordinary Least Squares }\end{array}$ \\
\hline Constant IGE $\mathrm{e}_{\mathrm{e}}$ & $\begin{array}{l}\text { Two-step estimator } \\
\text { Estimation of Equation [2] in two steps: } \\
\text { 1. Nonparametric estimation of } \ln E(Y \mid \ln x) \text { at } 100 \text { values of } X \\
\text { by computing In mean } Y \text { and } \ln \text { mean } X \text { within centile bins of } X \\
\text { 2. OLS regression of the estimated } \ln E(Y \mid \ln x) \text { on } \ln x\end{array}$ & $\begin{array}{l}\text { PPML estimator } \\
\text { Estimation of Equation [2] by Pseudo Maximum Likelihood, using } \\
\text { the log-likelihood function of a Poisson regression }\end{array}$ \\
\hline Nonparametric $\mathrm{IGE}_{\mathrm{g}}$ & $\begin{array}{l}\text { Two-step estimator } \\
\text { 1. Nonparametric estimation of } 100 \text { points in the intergenerational } \\
\text { curve defined by Equation [7] by computing mean In } Y \text { and In } \\
\text { mean } X \text { within centile bins of } X \\
\text { 2. Numerical computation of average slope of the curve }\end{array}$ & $\begin{array}{l}\text { Two-step estimator } \\
\text { 1. Nonparametric estimation of } 196 \text { points in the intergenerational } \\
\text { curve defined by Equation [7] based on a local polynomial } \\
\text { regression of In } Y \text { on } \ln X \\
\text { 2. Numerical computation of average slope of the curve }\end{array}$ \\
\hline Nonparametric $\mathrm{IGE}_{\mathrm{e}}$ & $\begin{array}{l}\text { Two-step estimator } \\
\text { 1. Nonparametric estimation of } 100 \text { points in the intergenerational } \\
\text { curve defined by Equation [6] by computing In mean } Y \text { and In } \\
\text { mean } X \text { within centile bins of } X \\
\text { 2. Numerical computation of average slope of the curve }\end{array}$ & $\begin{array}{l}\text { Two-step estimator } \\
\text { 1. Nonparametric estimation of } 196 \text { points in the intergenerational } \\
\text { curve defined by Equation [6] based on a local polynomial } \\
\text { regression of } Y \text { on } X \\
\text { 2. Numerical computation of average slope of the curve }\end{array}$ \\
\hline
\end{tabular}

Figure 2: Estimators. To estimate all IGEs, the long-run variables in Equations (1), (2), (6), and (7) are replaced by proxy short-run variables.

although there is disagreement on how many years are necessary to eliminate most of it (see Mitnik et al. 2018:9-15; see also Appendix F in our online supplement).

Mitnik and Grusky (2017) showed that a third bias looming over the estimation of the constant $\mathrm{IGE}_{g}$ is selection bias. Mobility scholars have addressed what they have perceived as the practical problem of the logarithm of zero being undefined with the expedient of dropping children with zero income from samples. ${ }^{19}$ As a result, estimation of that IGE with short-run proxy measures typically involves the use of a "censored sample," which generates a well-understood form of selection bias (e.g., Heckman 2008); as a large share of children have zero short-run income, the magnitude of this bias may be substantial (for details, see Mitnik and Grusky 2017). ${ }^{20}$ Mitnik and Grusky (2017) have shown that there is no attractive workaround for this problem. ${ }^{21}$

The $\mathrm{IGE}_{e}$ is immune to the selection bias affecting the $\mathrm{IGE}_{g}$, as its estimation with short-run proxy measures does not require dropping children with zero income from samples. At the same time, Mitnik (2017a) advanced and empirically validated a generalized error-in-variables model, indicating that the use of proxy measures makes estimation of the constant $\mathrm{IGE}_{e}$ with the PPML estimator vulnerable to life-cycle and attenuation biases very similar to those affecting estimation of the constant $\mathrm{IGE}_{g}$ with the OLS estimator. He also showed that the same strategies employed with the $\mathrm{IGE}_{g}$ to eliminate, or at least greatly reduce, those biases can be expected to be effective when estimating the constant $\mathrm{IGE}_{e}$.

Neither a formal measurement model nor empirical evidence on the methodological issues at hand is available for the estimation of the nonparametric IGEs with short-run proxy variables. Nevertheless, we expect that the same biases affecting estimation of the constant IGEs will be at play in the case of the nonparametric IGEs. 


\section{Data and Variables}

The SOI-M Panel, described in detail by Mitnik et al. (2015), is based on tax returns and other administrative data (e.g., W-2 and 1099 forms). It represents all children born between 1972 and 1975 who were living in the United States in 1987 and includes parental income information collected when the children were between 15 and 23 years old and children's income information, starting at age 26, for the period of 1998 to 2010. Almost all empirical results we present here are based on the SOI-M Panel. In our analyses, we use information on children's income pertaining to 2010, when they were between 35 and 38 years old, and to 2004, when they were between 29 and 32 years old.

Our exclusive concern in this article is with IGEs of (pretax) family income. The income measures employed in our analyses are annual measures in the case of children (either for 2010 or for 2004) and averages over several years in the case of parents. We use a measure of parental income based on nine years of parental information (pertaining to when the children were 15 to 23 years old) as well as a five-year measure (pertaining to when the children were 15 to 19 years old).

We exclude from our analyses children with (1) negative income; (2) income of more than $\$ 7,000,000$; (3) more than two years (in the case of the five-year measure) or three years (in the case of the nine-year measure) of missing parental information; (4) nonpositive average parental income; or (5) average parental income of more than $\$ 7,000,000$. Depending on which income measures (for both parents and children) are used, these sample selection rules generate four samples that differ slightly in size and demographic composition (children's mortality between 2004 and 2010 also plays a minor role). Using an obvious nomenclature, we refer to them as the 2004-5y, 2004-9y, 2010-5y, and 2010-9y samples. ${ }^{22}$ Descriptive statistics for the four samples are shown in Tables 1 and 2. Table 1 reports the number of observations and the gender and age of the children included in each sample, the origin of their income information, and the number of missing years of parental information among those retained. Table 2 shows the weighted means and standard deviations of the income variables, for children and parents, and of parental age (the SOI-M Panel is based on a stratified random sample of 1987 tax returns, so all our analyses employ sampling weights). The income variables are expressed in 2010 dollars using the Consumer Price Index for Urban Consumers, Research Series (CPI-U-RS).

For some more limited purposes, we also use aggregate statistics that Chetty et al. (2014) have made publicly available (see the sources in Table 3). The microdata underlying those statistics-which are the microdata used by Chetty et al. (2014) in their research-represent the birth cohorts of 1980 to 1982. Here, the children's income is their average income in 2011 and 2012, when they were between 29 and 32 years old, and their parental income is measured by averaging five years of information when they were between 14 and 20 years old. Income refers to (pretax) family income in both cases. 
Table 1: Demographic statistics, income sources, and missing information (unweighted percentages).

Child's gender (\% female)

Child's age

$$
29
$$

30

31

32

35

36

37

38

Child's income information

Tax return

W-2 and 1099 forms

CPS-based imputation

Number of missing years of parental information

0

1

2

3

Sample size

$$
\text { Samples }
$$

\begin{tabular}{llll}
$2004-5 y$ & $2004-9 y$ & $2010-5 y$ & $2010-9 y$ \\
\hline 49.3 & 49.2 & 49.5 & 49.4
\end{tabular}

\section{7}

$\begin{array}{llll}3.6 & 3.6 & 4.2 & 4.1\end{array}$

88.8

$\begin{array}{llll}5.8 & 5.8 & 7.1 & 7.1\end{array}$

Note: Children with more than two or three missing years of parental information are excluded from samples in which sample selection rules are applied with the five- or the nine-year parental-income measures, respectively.

\section{Key Differences in Samples and Methodological Decisions and Their Expected Effects on Estimates}

There are four differences between the samples used and the methodological decisions made in Chetty et al.'s (2014) research and in ours that can be expected to generate differences in estimates. The first three pertain to the ages of the children relied on to produce preferred estimates, the number of years of parental information employed to construct parental income measures for the same purpose, and the treatment of children without tax or other administrative information on their income. The fourth difference, which is of a different nature, involves decisions on the summary mobility measures that are important to estimate given overall research goals. We discuss these differences and their expected effects on estimates in turn. 
Table 2: Income and parental-age statistics (weighted values).

\begin{tabular}{lcccc}
\hline & \multicolumn{4}{c}{ Samples } \\
& $2004-5 y$ & $2004-9 y$ & $2010-5 y$ & $2010-9 y$ \\
\cline { 2 - 5 } Child's total income, $\$$ & 55,121 & 55,370 & 69,145 & 69,329 \\
$\quad$ Mean & 75,838 & 75,677 & 107,983 & 107,061 \\
$\quad$ Standard deviation & & & & \\
Average parental total income, \$ & 72,097 & 74,933 & 72,002 & 74,826 \\
$\quad$ Mean & 107,330 & 116,052 & 106,540 & 115,622 \\
$\quad$ Standard deviation & & & & \\
& & & & \\
Average parental age & 43.5 & 45.3 & 43.5 & 45.3 \\
$\quad$ Mean & 6.3 & 6.2 & 6.3 & 6.2 \\
$\quad$ Standard deviation & & & \\
\hline
\end{tabular}

Notes: Children with more than two or three missing years of parental information are excluded from samples in which sample selection rules are applied with the five- or the nine-year parental-income measures, respectively. Monetary values are in 2010 dollars (adjusted by inflation using the CPI-U-RS).

\section{Children's Ages and Parental Income Measures}

A central goal of the research by Chetty et al. (2014) was to study mobility within quite small geographic areas. To this end, they relied on the full population of tax records-which are only available starting in 1996-to construct the very large data set (i.e., a data set with close to 10 million observations) employed in their core analyses. In contrast, here our focus is on the correct estimation of national-level IGEs, and to this end we rely on the SOI-M Panel's 2010-9y sample, which has close to 12,500 observations. For reasons that will become clear later, we refer to this sample as the "SOI-M best sample."

Figure 3 allows one to compare this sample to the data employed by Chetty et al. (2014). The figure makes apparent two differences that are of central interest in light of our previous discussion of life-cycle and attenuation biases. First, whereas the children in Chetty et al.'s data are in their early 30s when their income is measured, those in the SOI-M best sample are in their late 30s (i.e., much closer to the age the literature has deemed optimal). This suggests that Chetty et al.'s estimates may be substantially downward biased, whereas ours should be much less affected by life-cycle bias. Importantly, although Chetty et al. (2014) emphatically denied that their IGE estimates were significantly impinged by this bias, in agreement with Mazumder (2016), we find the evidence they provided to support their claim flawed (see Appendix $\mathrm{E}$ in the online supplement).

Second, Chetty et al.'s measure of parental income is based on five years of information, whereas the corresponding measure in the SOI-M best sample is based on nine years. In his very influential article, Mazumder (2005) argued that up to 16 years of information are needed to eliminate or nearly eliminate attenuation bias; although this is likely to be an overestimate (see Appendix F in the online supplement), there is a rather broad consensus that five years of information is not enough to secure good estimates of the (constant) IGE . Similarly, Mitnik (2017a) 
Table 3: Baseline IGE estimates.

\begin{tabular}{lccc}
\hline & \multicolumn{2}{c}{$\begin{array}{c}\text { Chetty et al.'s } \\
(2014) \text { data }\end{array}$} & SOI-M best sample \\
\cline { 2 - 4 } IGE $_{e}$ & & \\
$\quad$ Constant & $0.34^{a}$ & $0.46^{b}$ & \\
& $(0.32-0.35)$ & $(0.43-0.49)$ & \\
Nonparametric & $0.38^{c}$ & $0.50^{b}$ & \\
& $(\mathrm{n} / \mathrm{a})$ & $(0.45-0.54)$ & \\
IGE $_{g}$ & & Lower-bound & Upper-bound \\
Constant & $0.34^{a}$ & $0.46^{b}$ & $0.67^{b}$ \\
Nonparametric & $0.34-0.34)$ & $(0.40-0.51)$ & $(0.59-0.75)$ \\
& $0.39^{c}$ & $0.53^{b}$ & $0.74^{b}$ \\
& $(\mathrm{n} / \mathrm{a})$ & $(0.48-0.58)$ & $(0.66-0.80)$ \\
\hline
\end{tabular}

Notes: 95 percent confidence intervals are in parentheses. Appendix D in the online supplement provides information on the computation of confidence intervals and explains why they are not available in some cases. With the SOI-M best sample, lower- and upper-bound estimates of the IGE $_{g}$ are those in which CPS nonadmins with zero income are dropped and assigned \$1, respectively, when computing values for the mean imputation of log income to nonadmin children. Sources: ${ }^{a}$ Chetty et al. (2014:1574 and Online Appendix C for the $\mathrm{IGE}_{e}$; Table 1 for the $\left.\mathrm{IGE}_{g}\right) .{ }^{b}$ Estimated by the authors using the SOI-M best sample. ${ }^{c}$ Estimated by the authors using data available at https://opportunityinsights.org/data/ ("Geography of Mobility: National Statistics by Parent or Child Income Percentile").

reported that approximately 13 years of information are needed to eliminate the bulk of attenuation bias when estimating the (constant) IGE $_{e}$ with survey data (although, for reasons discussed in Appendix $\mathrm{F}$ in the online supplement, it is very likely that fewer years are needed with administrative data). This suggests that Chetty et al.'s IGE estimates may be significantly reduced by attenuation bias, whereas ours should be much less affected. Although Chetty et al. (2014) strongly rejected that their estimates of the constant $\mathrm{IGE}_{g}$ are affected by attenuation bias, their evidence for their claim that five years of parental information is enough to eliminate the bulk of that bias is quite weak (see Appendix G in the online supplement).

\section{Nonadmin Children}

The third key difference concerns the treatment of nonfiling children without other administrative income information. In any tax year, a number of people do not file taxes, mostly because their incomes are below the thresholds that make filing mandatory. Not surprisingly, then, not all children included in Chetty et al.'s (2014) data and in the SOI-M best sample filed taxes in the tax years when their income was measured. ${ }^{23}$ To address this problem, both Chetty et al. (2014) and Mitnik et al. (2015) — the latter, when building the SOI-M Panel—resorted to other administrative sources (e.g., earnings from $\mathrm{W}-2$ forms and unemployment-insurance income from 1099 forms) to approximate the income of some nonfiling children. For other nonfiling children, however, alternative administrative information was not available. 
Year

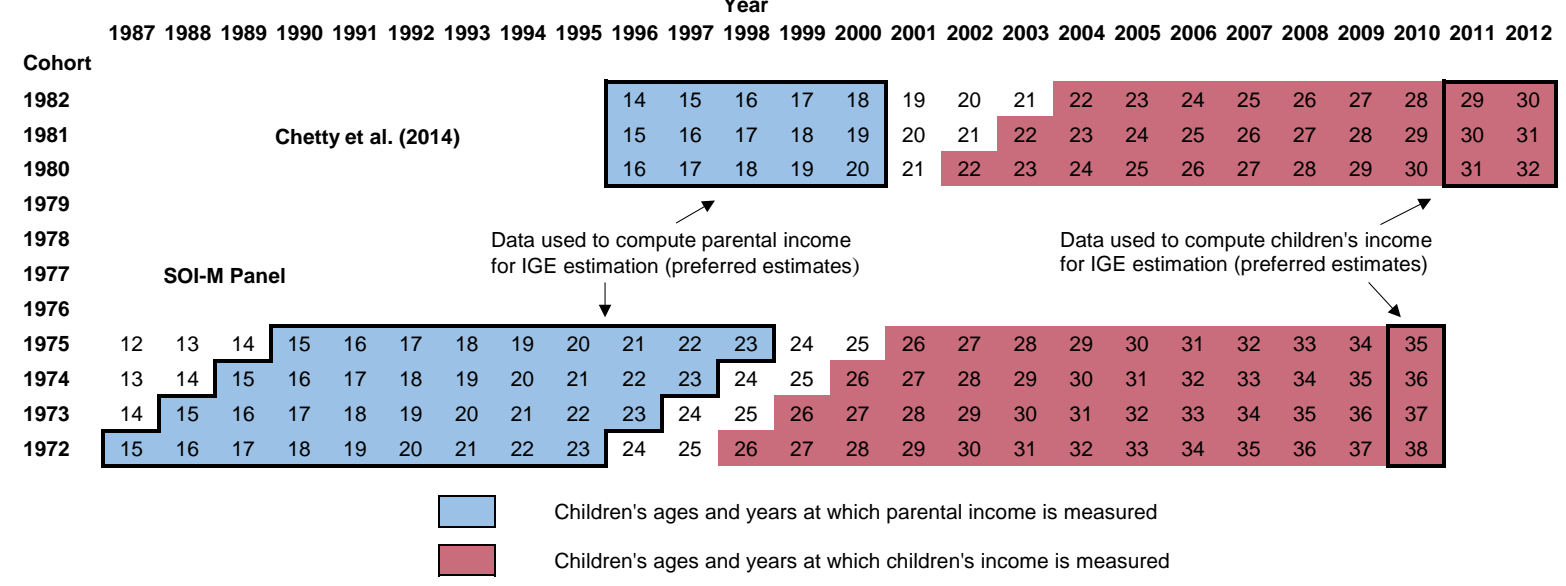

Figure 3: Comparison of Chetty et al.'s (2014) data and the SOI-M best sample.

As a result, 6.1 percent of the children in Chetty et al.'s core sample (2014:Online Appendix Table 3) and 7.1 percent of the children in the SOI-M best sample (Table 1) are nonfilers without other administrative information. In what follows, we refer to this subset of nonfiling children as "nonadmin children" or just "nonadmins."

Although nonadmin children may have some income-mostly from work in the informal economy and transfers from sources not covered in constructing the income measures (e.g., Temporary Assistance to Needy Families)—Chetty et al. (2014) opted for assigning them an income of zero. This can be expected to generate an upward bias in the estimation of the $\mathrm{IGE}_{e}$, as it underestimates the income of nonadmin children, whose share decreases sharply as parental income increases (see, e.g., Chetty et al. 2014:Figure 1). The notable robustness of the $\mathrm{IGE}_{e}$ to the treatment of nonadmins (Mitnik et al. 2018:30-33) indicates, however, that this bias should be small. In contrast, the estimation of the $\mathrm{IGE}_{g}$ becomes very problematic under this approach. The reason is that it requires dropping nonadmin children, which in turn means that the resulting estimates can be expected to be seriously affected by the selection bias discussed by Mitnik and Grusky (2017). Chetty et al. did acknowledge that dropping nonadmins from the sample "overstates the degree of intergenerational mobility" (Chetty et al. 2014:1573). However, it is clear that they deemed any ensuing selection bias small-in particular, small enough to make comparisons between the resulting estimates and previous estimates in the literature perfectly meaningful. Indeed, not only did Chetty et al. (2014) make the estimates they obtained by dropping nonadmin children from their sample their preferred estimates, but they also argued that these estimates were "broadly consistent with previous results, with the exception of Mazumder's (2005) and Clark's (2014) IGE estimates, which imply much lower levels of intergenerational mobility" (Chetty et al. 2014:1558). ${ }^{24}$

Instead of assigning an income of zero to nonadmin children, we resort to data from the Annual Social and Economic Supplement (ASEC) of the Current Population Survey (CPS) to carry out mean imputation. These CPS-ASEC data 
include information on "likely nonfilers," who are identified using a tax simulation model developed by the U.S. Census Bureau. Using this information, we compute the mean income of likely nonadmin children separately for each of six gender-age groups in the SOI-M Panel (see Appendix $\mathrm{H}$ in the online supplement). Then, under the assumption that the expectation of nonadmin children's income is independent of parental income, we assign those mean values to the corresponding nonadmin children and use the resulting income variables to estimate the $\mathrm{IGE}_{e}$.

Implementing the mean-imputation strategy with the $\mathrm{IGE}_{g}$ is less straightforward. The reason is that approximately one-third of the CPS likely nonfilers without earnings or unemployment-insurance income-or "CPS nonadmins," for shorthave zero family income. As in this context it's necessary to impute the mean of the logarithm of income (rather than mean income), CPS nonadmins with zero reported income pose a problem. The mobility literature suggests two approaches for addressing it. The first approach is to assume that zero reported income is the result of a mechanism unrelated to true income and therefore that those with zero income may be unproblematically dropped when computing average log income. This is, of course, equivalent to the assumption mobility scholars have almost always made, implicitly, when estimating the $\operatorname{IGE}_{g}$ (and which generates the downward selection bias discussed by Mitnik and Grusky [2017]). The second approach is to assume that zero reported income does not reflect true income but is nevertheless indicative of very low positive income; this is the assumption implicitly made in those very few cases in which the standard approach for estimating the $\mathrm{IGE}_{g}$ was deemed problematic and which typically manifested itself in the assignment of an income of $\$ 1$ to children with zero reported income (e.g., Couch and Lillard 1998). Using these two approaches to compute the mean log income of CPS nonadmins within each gender-age group, we generate a set of upper and a set of lower imputation values, respectively, and employ them to conduct mean imputation (see Appendix $\mathrm{H}$ in the online supplement). As we have independent evidence (for the constant $\mathrm{IGE}_{g}$ ) that the estimates that result bracket the true value of the elasticity, we interpret them as lower- and upper-bound estimates, respectively, of the IGE ${ }_{g} \cdot{ }^{25}$

Mean imputation is an approach methodologically superior to zero imputation. Although it may be expected to make a small difference for $\mathrm{IGE}_{e}$ estimates-which, as already indicated, are very robust to the treatment of nonadmin children-it can be expected to make a substantial difference for the estimation of the $\mathrm{IGE}_{g}$.

\section{Summary Mobility Measures}

Chetty et al. (2014) and Mitnik et al. (2018) have argued that intergenerational curves are markedly nonlinear in log-log space. Moreover, the evidence they offered-especially the nonparametric curves Chetty et al. (2014) estimated, which are based on binned scatter plots relying on millions of observations-is rather conclusive. In contrast, the constant IGE conventionally estimated by mobility scholars assumes a linear relationship. As it should be apparent, however, a constant IGE is a poor summary measure of economic mobility and persistence when the true curve is far from linear (Bratsberg et al. 2007). 
As Chetty et al.'s (2014) main goal wasn't the estimation of the share of economic inequality transmitted across generations in the United States but the study of geographic variability in mobility within the country, their response to the finding that the $\mathrm{IGE}_{g}$ is markedly nonlinear (and to the estimation difficulties generated by nonadmin children) was to switch to a different measure not affected by those problems for the bulk of their analyses. ${ }^{26}$ This strategy was justified in light of their main goal. Here, however, our main goal is the estimation of national-level IGEs. Therefore, the finding of marked nonlinearities requires that we estimate nonparametric IGEs. With respect to our goal, estimates based on the constantelasticity assumption are affected by functional-form bias. Thus, in the specific sense just discussed, the IGE estimates reported by Chetty et al. (2014) should be affected by functional-form bias. The presence of this bias should contribute to accounting for the differences between those estimates and our preferred IGE estimates.

\section{Empirical Analyses}

We have claimed that Chetty et al.'s (2014) IGE estimates should be affected by life-cycle, attenuation, and functional-form biases and, more generally, that IGE estimates based on their data should be affected by the first two biases. We have also claimed that $\mathrm{IGE}_{g}$ estimates based on their data should be affected by selection bias, whereas $\mathrm{IGE}_{e}$ estimates should be affected by what we may refer to as imputation bias (because of the imputation of zero income to nonadmin children). Lastly, we have argued that IGE estimates based on the SOI-M best sample should be essentially unaffected by selection and imputation biases and not much affected by life-cycle and attenuation biases; it follows that those estimates should be substantially higher than estimates based on Chetty et al.'s data. ${ }^{27}$ We now make the empirical case for our claims. We start by providing baseline estimates of both the $\mathrm{IGE}_{e}$ and the $\mathrm{IGE}_{g}$ of family income based on our and on Chetty et al.'s (2014) data. Next, we resort to a sample from the SOI-M Panel that allows us to replicate the key bias-generating features of Chetty et al.'s data and show that it leads to IGE estimates that are much lower than those obtained with the SOI-M best sample and quite close to those based on Chetty et al.'s data. After that, we conduct Shapley decompositions (Shorrocks 2013) to quantify the specific contribution of each bias. All estimates pertain to men and women pooled.

\section{Baseline Estimates}

The top panel of Table 3 presents baseline $\mathrm{IGE}_{e}$ figures. The first column shows Chetty et al.'s (2014) estimate of the constant $\mathrm{IGE}_{e}$ and our estimate of the nonparametric $\mathrm{IGE}_{e}$ using Chetty et al.'s data. These estimates are 0.34 and 0.38 , respectively. The second column shows our estimates of the $\mathrm{IGE}_{e}$ based on the SOI-M best sample. At 0.46 and 0.50 , these estimates are 35 percent (constant $\mathrm{IGE}_{e}$ ) and 32 percent (nonparametric $\mathrm{IGE}_{e}$ ) larger than the corresponding estimates based on Chetty et al.'s data. Moreover, our nonparametric estimate-that is, our preferred estimate-based on the SOI-M best sample is almost 50 percent larger than the $\mathrm{IGE}_{e}$ 
estimate reported by Chetty et al. (2014) under the constant-elasticity assumption (0.50 compared to 0.34 ).

The bottom panel of Table 3 presents baseline IGE $_{g}$ figures. Chetty et al.'s (2014) estimate of the constant $\mathrm{IGE}_{g}$ and our estimate of the nonparametric $\mathrm{IGE}_{g}$ using Chetty et al.'s data are again in the first column. As noted above, these estimates were obtained by dropping nonadmin children. The next two columns show our lower- and upper-bound estimates based on the SOI-M best sample. These estimates put the constant $\mathrm{IGE}_{g}$ in the 0.46 to 0.67 range and the nonparametric IGE in the 0.53 to 0.74 range. The corresponding estimates based on Chetty et al.'s (2014) data are 0.34 and 0.39 . This means that even our lower-bound estimates are about 35 percent larger than the corresponding estimates based on Chetty et al.'s data and methodological decisions. Moreover, our lower-bound nonparametric estimate is a full 56 percent larger than the $\mathrm{IGE}_{g}$ estimate reported by Chetty et al. (2014) under the constant-elasticity assumption (0.53 compared to 0.34$)$. The difference is, of course, much larger when we consider our upper-bound estimate.

\section{Baseline Estimates Compared to Estimates Based on Replication Data from the SOI-M Panel}

The results of Table 3 are consistent with our hypothesis that Chetty et al.'s (2014) data lead to downward-biased $\mathrm{IGE}_{e}$ estimates. To provide evidence for this hypothesis, we next resort to an SOI-M Panel sample replicating the key bias-generating features of Chetty et al.'s data. If we are on the mark, we should produce with this sample much lower $\mathrm{IGE}_{e}$ estimates than those obtained with the SOI-M best sample.

Figure 4 shows how we approximate two features of Chetty et al.'s data that, we have argued, generate (or exacerbate) life-cycle and attenuation biases. First, we use the children's family-income information for 2004, when they were between 29 and 32 years old (the same ages as the children in Chetty et al.'s sample). Second, like Chetty et al., we employ a parental income measure based on five years of information. The resulting sample is the 2004-5y sample we described earlier. In addition, to further mirror Chetty et al.'s approach, we substitute zeros for the CPS-based mean income values imputed to nonadmin children in the SOI-M Panel data. We refer to the resulting sample as the "SOI-M all-biases sample."

Figure 5 shows the $\mathrm{IGE}_{e}$ estimates produced with this sample together with the corresponding estimates from Table 3 . At 0.38 and 0.41 , the new estimates of the constant and nonparametric $\mathrm{IGE}_{e}$ are substantially smaller than those obtained with the best sample and-particularly for the latter estimate-quite close to those based on Chetty et al.'s data. The results in Figure 5 suggest that between twothirds (constant $\mathrm{IGE}_{e}$ ) and three-quarters (nonparametric $\mathrm{IGE}_{e}$ ) of the within-model differences in estimates are accounted for by life-cycle, attenuation, and imputation biases affecting the estimates based on Chetty et al.'s data. ${ }^{28}$ Likewise, the results suggest that, depending on the computation method used, the aforementioned biases plus functional-form bias account for between three-quarters and more than four-fifths of the difference between (1) our nonparametric (i.e., preferred) $\mathrm{IGE}_{e}$ estimate based on the SOI-M best sample and (2) the $\mathrm{IGE}_{e}$ estimate reported 
Year

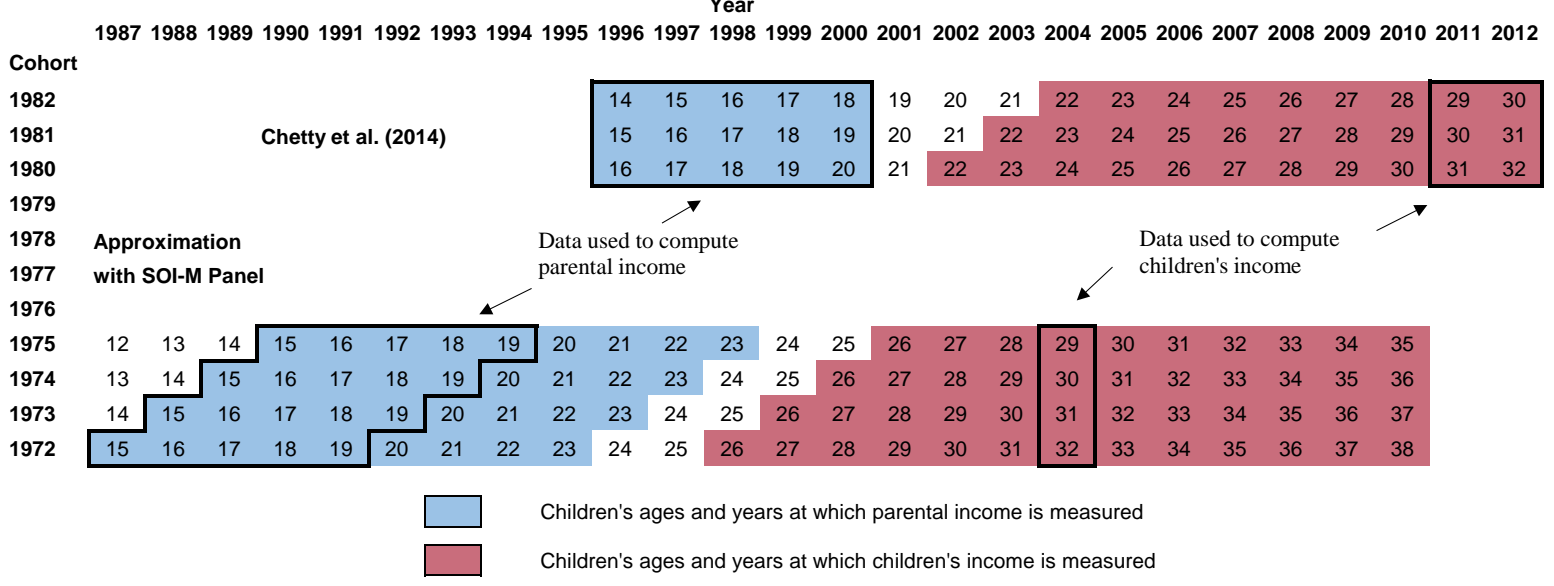

Figure 4: Chetty et al.'s (2014) children's ages and parental-income measure approximated with data from the SOI-M Panel. 
0.60

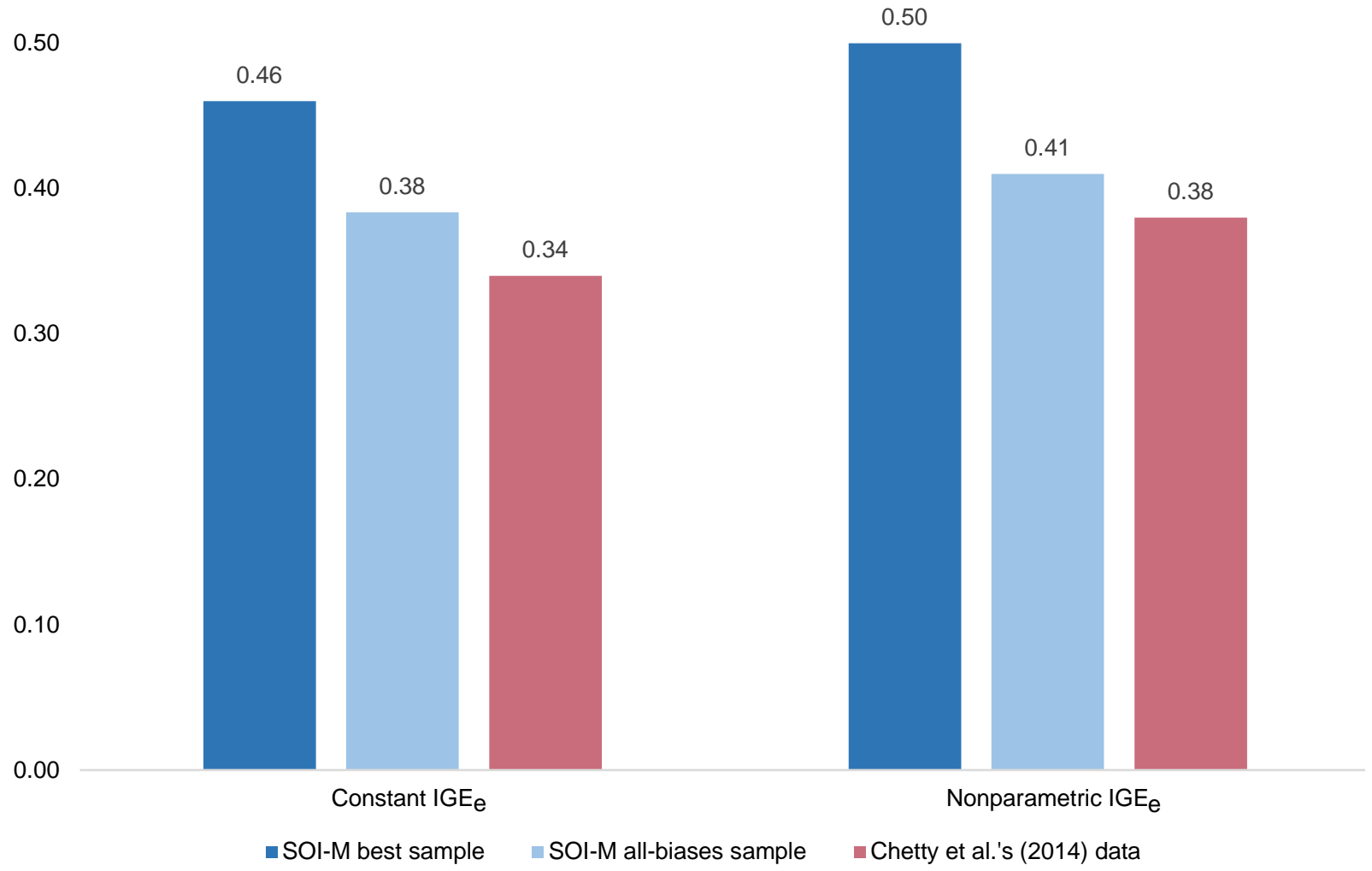

Figure 5: Estimates of the IGE of the expectation based on the SOI-M best sample, the SOI-M all-biases sample, and Chetty et al.'s (2014) data.

Figure 6 shows the results together with the corresponding estimates based on Chetty et al.'s (2014) data and the corresponding lower- and upper-bound estimates based on the SOI-M best sample. The estimates of the constant and nonparametric $\mathrm{IGE}_{g}$ generated with the SOI-M two-year all-biases sample are 0.30 and 0.40 , respectively, which means that they are much smaller than (even) the lower-bound estimates obtained with the SOI-M best sample. They are also quite close to the estimates based on Chetty et al.'s data; in fact, the nonparametric estimates are almost identical. And, as anticipated, they are slightly larger (on average, 7.6 percent larger) than the estimates based on the SOI-M all-biases sample, which relies on only one year of children's information and therefore overstates selection bias.

Figure 6 suggests that between two-thirds (constant $\mathrm{IGE}_{g}$ ) and more than ninetenths (nonparametric $\mathrm{IGE}_{g}$ ) of the within-model lower-bound differences in estimates are accounted for by life-cycle, attenuation, and selection biases affecting 


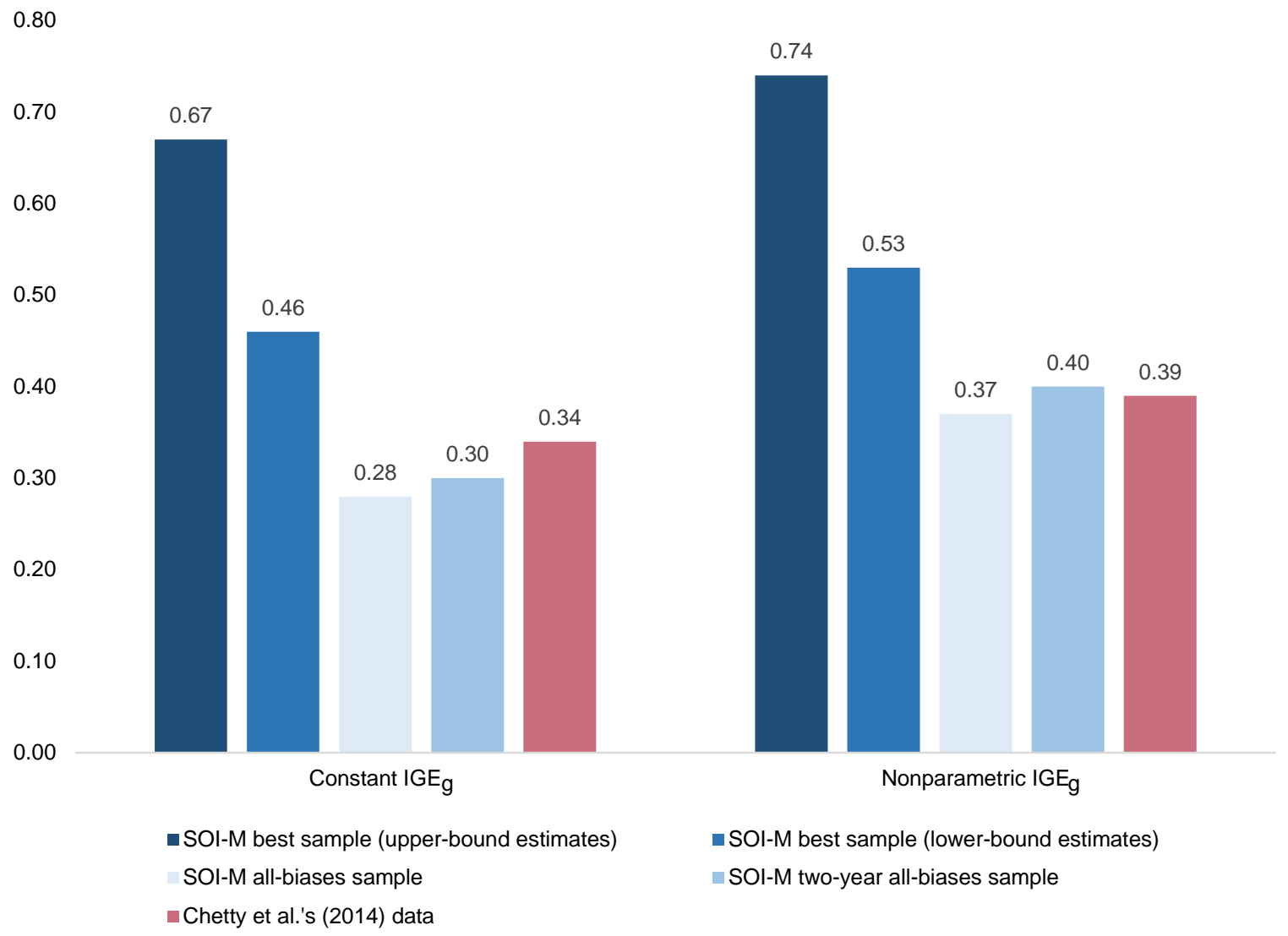

Figure 6: Estimates of the IGE of the geometric mean based on the SOI-M best sample, the SOI-M all-biases samples, and Chetty et al.'s (2014) data.

the estimates based on Chetty et al.'s data. ${ }^{30}$ Similarly, the figure suggests that, depending on the computation method used, these three biases plus functional-form bias account for between 80 percent and 95 percent of the difference between (1) the (constant) IGE $_{g}$ estimate reported by Chetty et al. (2014) and (2) our lower-bound estimate of the nonparametric $\mathrm{IGE}_{g} \cdot{ }^{31}$ As before, the residual differences that are left unexplained are most likely due to sampling variability, the discrepancy in periods and cohorts, and small differences in methodological decisions. Of course, those residual differences become much smaller in proportional terms (if not essentially nil) if instead of comparing Chetty et al.'s (2014) estimates with our lower-bound estimates we compare them with our upper-bound estimates. For instance, the four biases account for between 90 percent and 97.5 percent of the difference between the constant $\mathrm{IGE}_{g}$ estimate reported by Chetty et al. (2014) and our upper-bound nonparametric IGE estimate. $^{32}$ 


\section{Shapley Decompositions}

In Figure 5 we introduced, for each model, all bias-generating features at once, which does not allow one to compute the size of each individual bias or even provide evidence that all biases we posited in the case of the $\mathrm{IGE}_{e}$ are really at play and have the expected signs. We use the 2004-5y, 2004-9y, 2010-5y, and 2010-9y samples described earlier to identify the direction and magnitude of each individual bias. For this purpose, we take estimates based on the 2010-9y sample to be free of life-cycle and attenuation biases, those based on the 2004-5y sample to be affected by both biases, and those based on the other two samples to be each affected by one bias but not the other. In each of the four samples, we may either keep the CPS-based mean imputation for nonadmin children's income or replace it with $\$ 0$ imputation (so as to capture the bias generated by the latter imputation). And, in each case, we may estimate the $\mathrm{IGE}_{e}$ under the constant-elasticity assumption or estimate it nonparametrically (so as to capture functional-form bias). There are therefore 16 possible combinations of sample, imputation, and model, each of which can be used to obtain an $\mathrm{IGE}_{e}$ estimate affected by a specific set of biases. ${ }^{33}$ Comparing the estimates produced with any two of such combinations, differing only in that one is affected by a bias that the other avoids, allows us to compute the marginal effect of introducing the feature generating that bias (given a common set of other bias-generating features). The size of each bias, however, cannot be determined by simply introducing all bias-generating features in some arbitrary order, and computing the difference in estimates that results from adding each one in turn, as the effect of introducing each bias-generating feature depends on which others are already present. For this reason, we instead do a Shapley decomposition (Shorrocks 2013) of the total bias, whereby the size of each bias is defined as its average marginal contribution to total bias across all possible orders in which the four bias-generating features can be introduced. In such a decomposition, the sum of the individual biases is guaranteed to be equal to the total bias.

Table 4 shows the results of computing model-specific Shapley decompositions of total bias. As expected, the life-cycle and attenuation biases are downward biases (so their contributions to total bias are positive), whereas the imputation bias is an upward bias (so its contribution to total bias is negative). For both the constant and nonparametric estimates, the contribution of the life-cycle bias to total bias is about twice as large as that of the attenuation bias. And although the imputation bias is much smaller in absolute value than the other two biases, it still is the case that the use of zero imputation rather than mean imputation reduces total bias by about 15 percent. $^{34}$

Table 5 shows the results of the across-models Shapley decomposition of total bias, which is defined as the difference between the nonparametric estimate based on the SOI-M best sample and the constant-elasticity estimate based on the SOI$\mathrm{M}$ all-biases sample. The signs of the contributions of the attenuation, life-cycle, and imputation biases are the same as in the model-specific decompositions. The contribution of the functional-form bias is positive, indicating that it is a negative bias (as expected). As in Table 4, the contribution of the life-cycle bias is the largestabout twice as large as those of the attenuation and functional-form biases. Here, the imputation bias reduces total bias by about 8 percent. ${ }^{35}$ If, for the sake of simplicity, 
Table 4: Model-specific Shapley decompositions of total bias in $\mathrm{IGE}_{e}$ estimation.

Total bias

Attenuation bias

Life-cycle bias

Imputation bias

\begin{tabular}{cccc}
\multicolumn{2}{c}{ Constant IGE } & \multicolumn{2}{c}{ Nonparametric IGE $_{e}$} \\
Value & Percent & Value & Percent \\
\hline 0.08 & 100.0 & 0.09 & 100.0 \\
0.03 & 42.2 & 0.03 & 36.6 \\
0.06 & 74.8 & 0.07 & 79.5 \\
-0.01 & -17.0 & -0.01 & -16.1 \\
\hline
\end{tabular}

Note: Total bias is the difference between an estimate based on the SOI-M best sample and the corresponding estimate based on the SOI-M all-biases sample (see Figure 5).

we ignore this bias, then the life-cycle bias contributes about half of the total bias, whereas the attenuation and functional-form biases contribute about one-quarter each.

The foregoing results provide strong evidence that the bulk of the difference between Chetty et al.'s (2014) constant $\mathrm{IGE}_{e}$ estimate and our nonparametric $\mathrm{IGE}_{e}$ estimate based on the SOI-M best sample (see Table 3) is due to the combined effects of life-cycle, attenuation, imputation, and functional-form biases affecting the former estimate, with life-cycle bias making the largest contribution to that difference. Importantly, in Appendix I in the online supplement, we show that our key attenuation-bias result so far (i.e., that five years of parental information is not enough to eliminate the bulk of attenuation bias in the case of the $\mathrm{IGE}_{\mathcal{e}}$ ) is robust to alternative ways of examining this bias. We also provide evidence suggesting that our $\mathrm{IGE}_{e}$ estimates are (nearly) free of attenuation bias.

Computing Shapley decompositions of total bias is more complicated in the case of the $\mathrm{IGE}_{g}$. Indeed, to properly capture the effects of life-cycle, attenuation, functional-form, and selection bias on the estimates based on Chetty et al.'s (2014) data and methodological decisions, all estimates should be obtained with two-year samples. However, for reasons explained in Appendix J in the online supplement, proceeding this way is not feasible. As an alternative, we do the following: As we did in the case of the $\mathrm{IGE}_{e}$, for each estimate of total bias, we compute 16 estimates, one for each possible combination of sample, imputation, and model, using one-year samples in all cases. But before computing the Shapley decompositions, we adjust upward all estimates based on samples in which the CPS-based mean imputations for nonadmin children were replaced by zeros so as to reflect the fact that oneyear samples overestimate selection bias. After introducing these adjustments, we compute the Shapley decompositions as before. Importantly, with this approach, the total biases are exactly what is wanted in all cases (see Appendix J in the online supplement for details and the notes in Tables 6 and 7 for the definitions of the total biases of interest).

The top panel of Table 6 presents the model-specific Shapley decompositions of total bias with respect to our lower-bound estimates. As expected, the selection bias is a downward bias (so its contribution to total bias is positive). The life-cycle and attenuation biases also have their expected negative signs, as was the case with the $\mathrm{IGE}_{e}$. Unlike with the $\mathrm{IGE}_{e}$, however, the relative contributions of the attenuation and life-cycle biases vary significantly across models. The bottom panel of Table 6 
Table 5: Across-models Shapley decomposition of total bias in $\mathrm{IGE}_{e}$ estimation.

Total bias

Functional-form bias

Attenuation bias

\begin{tabular}{cc} 
Value & Percent \\
\hline 0.12 & 100.0 \\
0.03 & 28.0 \\
0.03 & 28.3 \\
0.06 & 55.7 \\
-0.01 & -12.1
\end{tabular}

Imputation bias

Note: Total bias is the difference between the nonparametric estimate based on the best SOI-M sample and the constant-elasticity estimate based on the SOI-M all-biases sample (see Figure 5).

presents the same decompositions but with respect to our upper-bound estimates, with all biases exhibiting the expected signs. Also as expected, both the absolute size and the relative importance of selection bias are now markedly larger in both models (selection bias is more than five times as large in size and more than twice as large in relative importance in both cases). The relative importance of attenuation bias is smaller, and that of life-cycle bias is much smaller (i.e., disproportionally smaller), in both models.

The top panel of Table 7 shows the results of the across-models Shapley decomposition of total bias with respect to our lower-bound estimates. As in the case of the $\mathrm{IGE}_{e}$, all biases-including functional-form bias-are downward biases. However, in that case, life-cycle bias accounted for roughly half of total bias, and the attenuation and functional-form biases accounted for roughly one-quarter each, whereas in the case of the $\mathrm{IGE}_{g}$, functional-form bias accounts for roughly two-fifths of total bias, and life-cycle, attenuation, and selection bias account for roughly one-fifth each. As expected, both the absolute and relative importance of selection bias increases markedly in the Shapley decomposition with respect to our upper-bound estimate, which is shown in the bottom panel of the same table. Here a full three-fifths of the difference is accounted for by selection bias, and the functional-form and attenuation biases account for most of the rest.

The foregoing results provide strong evidence that the bulk of the differences between Chetty et al.'s (2014) constant IGE $_{g}$ estimates and our preferred (i.e., nonparametric) $\mathrm{IGE}_{g}$ estimates, which we presented in Table 3, are due to the combined effects of life-cycle, attenuation, selection, and functional-form biases affecting the former estimates. Functional-form bias makes the largest contribution to those differences in the case of the lower-bound estimates, whereas selection bias makes the largest contribution in the case of the upper-bound estimates.

Like with the $\mathrm{IGE}_{e}$, in Appendix I in the online supplement, we show that our second key attenuation-bias result (i.e., that five years of information is not enough to eliminate the bulk of attenuation bias in $\mathrm{IGE}_{g}$ estimates) is robust to alternative ways of examining this bias. Unlike with the $\mathrm{IGE}_{e}$, however, we also show that although using nine years of information to estimate the $\mathrm{IGE}_{g}$ reduces that bias substantially, it is not likely to (nearly) eliminate it. This provides further support for our claim that Chetty et al.'s (2014) $\mathrm{IGE}_{g}$ estimates greatly understate true economic persistence as measured by that IGE concept. 
Table 6: Model-specific Shapley decompositions of total bias in $\mathrm{IGE}_{g}$ estimation.

\begin{tabular}{lcccc}
\hline Biases with respect to lower-bound estimates & \multicolumn{3}{c}{ Constant $\mathrm{IGE}_{g}$} & \multicolumn{2}{c}{ Nonparametric $\mathrm{IGE}_{g}$} \\
\cline { 2 - 5 } Total bias & 0.15 & 100.0 & 0.13 & 100.0 \\
Attenuation bias & 0.06 & 40.7 & 0.02 & 18.5 \\
Life-cycle bias & 0.04 & 27.8 & 0.06 & 43.7 \\
Selection bias & 0.05 & 31.5 & 0.05 & 37.8 \\
& \multicolumn{4}{c}{ Constant IGE } \\
Biases with respect to upper-bound estimates & \multicolumn{2}{c}{ Nonparametric IGE $\mathrm{IG}_{g}$} \\
& Value & Percent & Value & Percent \\
Total bias & 0.37 & 100.0 & 0.33 & 100.0 \\
Attenuation bias & 0.09 & 23.4 & 0.04 & 11.9 \\
Life-cycle bias & 0.01 & 3.3 & 0.04 & 11.6 \\
Selection bias & 0.27 & 73.3 & 0.26 & 76.6 \\
\hline
\end{tabular}

Note: Total bias is the difference between a lower-bound (top panel) or upper-bound (bottom panel) estimate based on the SOI-M best sample and the corresponding estimate based on the SOI-M two-year all-biases sample (see Figure 6).

\section{Discussion and Conclusions}

Assessing the extent to which economic advantages are transmitted across generations is quite a difficult endeavor. In the United States, IGE estimates cover a very wide range and are mostly based on survey data affected by many problems and limitations. Nevertheless, the balance of the evidence suggested until recently that as much as half, and possibly more, of economic advantages are passed on from parents to children. This view, which was greatly influenced by Mazumder's (2005) administrative-data estimates, was seriously challenged when Chetty et al. (2014) advanced a plausible argument to the effect that Mazumder's estimates were upward biased and provided tax-data estimates indicating that only one-third of family-income advantages are transmitted across generations.

Using a different tax-based data set better suited to the estimation of nationallevel IGEs, and a better approach for dealing with the nonadmins problem, we have provided new estimates of family-income IGEs (for men and women pooled). Our preferred nonparametric estimates put the IGE of expected income at 0.5 and the conventional IGE estimated in the literature in the 0.53 to 0.74 range (whereas the corresponding constant-elasticity estimates are about 10 percent lower).

We have also shown that Chetty et al.'s (2014) estimates of family-income IGEs and, more generally, IGE estimates based on their data and methodological decisions are downwardly biased because of the joint effects of attenuation, life-cycle, selection (in the case of the $\mathrm{IGE}_{g}$ ), and functional-form biases. The evidence we have provided, which relies on tax-based samples mirroring the bias-generating features of Chetty et al.'s tax data and methodological decisions, is strong. We used those samples both to generate estimates reproducing the bulk of the overall biases in the estimates based on Chetty et al.'s data and decisions and to isolate the absolute and relative contributions of each individual bias. 
Table 7: Across-models Shapley decomposition of total bias in $\mathrm{IGE}_{g}$ estimation.

\begin{tabular}{lcc}
\hline Biases with respect to lower-bound estimates & & \\
& Value & Percent \\
\cline { 2 - 3 } Total bias & 0.23 & 100.0 \\
Functional-form bias & 0.09 & 37.8 \\
Attenuation bias & 0.04 & 18.7 \\
Life-cycle bias & 0.05 & 21.5 \\
Selection bias & 0.05 & 21.9 \\
Biases with respect to upper-bound estimates & & \\
& & \\
Total bias & Value & Percent \\
Functional-form bias & 0.43 & 100.0 \\
Attenuation bias & 0.08 & 18.5 \\
Life-cycle bias & 0.06 & 14.2 \\
Selection bias & 0.03 & 6.2 \\
\hline
\end{tabular}

Note: Total bias is the difference between a lower-bound (top panel) or upper-bound (bottom panel) nonparametric estimate based on the best SOI-M sample and the constant-elasticity estimate based on the SOI-M two-year all-biases sample (see Figure 6).

We first focused on the IGE of expected income. Our results indicated that (1) between two-thirds and three-quarters of the within-model differences between our estimates and estimates based on Chetty et al.'s (2014) data are accounted by life-cycle, attenuation, and imputation biases affecting the latter, and (2) between three-quarters and four-fifths of the difference between our nonparametric estimate and the constant-elasticity estimate reported by Chetty et al. (2014) is accounted for by the same three biases plus functional-form bias. In all cases, life-cycle bias is the main driver behind the observed differences, attenuation bias and (when relevant) functional-form bias play important roles, and imputation bias makes the differences somewhat smaller (as this bias is positive rather than negative).

We next focused on the IGE concept conventionally considered in the literature. Our analyses indicated that (1) between two-thirds and more than nine-tenths of the within-model differences between our lower-bound estimates and estimates based on Chetty et al.'s (2014) data are accounted for by life-cycle, attenuation, and selection biases, and (2) between 80 percent and 95 percent of the difference between our lower-bound nonparametric estimate and the constant-elasticity estimate reported by Chetty et al. (2014) is accounted for by the same three biases plus functional-form bias. Here the main drivers of the observed differences vary across analyses, selection bias is substantial in all cases, and functional-form bias (when relevant) plays a larger role than in the case of the IGE of expected income. When we examined the differences with respect to our upper-bound estimates, the share of the differences accounted for by the four biases we have considered, as well as the relative importance of selection bias, increased substantially.

We have used high-quality tax data to show that, in the United States, at least half of economic advantages are transmitted across generations. In contrast with 
the estimates based on Chetty et al.'s (2014) data, the estimates based on the SOI-M best sample fully support the dominant hypothesis. In light of the novel share interpretation advanced in this article, our estimates indicate that, in the United States, at least half of income inequality among parents is transformed into inequality of opportunity among their children, regardless of whether we use the conditional expectation or the conditional geometric mean to define intergenerational curves and to index children's income opportunities. Our results also indicate that that share-that is, the rate at which income inequality is transformed into inequality of opportunity-may well be substantially larger than half when the conditional geometric mean is chosen as the opportunity index (as the mobility literature has implicitly done, at least until very recently).

Our results have a further implication for inequality of opportunity in a comparative perspective. We have demonstrated that inequality of opportunity (modulo parental income) is equal to the product of parental income inequality and economic persistence. As family-income inequality is larger in the United States than in all other highly developed countries (Gornick and Milanovic 2015), it's safe to assume that the country also ranks close to the top, if not at the very top, in terms of parental income inequality. Given that our empirical results are consistent with the notion that economic persistence in the United States is close to the highest, if not the highest, among such countries, it follows that there are good reasons to believe that there is a very high level of inequality of opportunity in the country compared to most other highly developed countries.

\section{Notes}

1 The IGE has almost always been estimated by assuming that it is constant across levels of parental income. Although strictly speaking a measure of the persistence of economic differences across generations (or economic persistence, for short), the constant IGE has been commonly interpreted as a measure of economic mobility as well (in which a high IGE signifies low mobility).

2 The IGE of women's earnings has been seldom estimated, in part because women's earnings are typically not considered to be a meaningful measure of their overall economic status (Chadwick and Solon 2002:335). One of the motivations for estimating the IGE of family income is that it makes it possible to circumvent this limitation.

3 See Appendix A in the online supplement for our discussion of Chetty et al.'s (2014) argument and Mazumder's (2016) response. Our main conclusions are that (1) Chetty et al. advanced a plausible empirical hypothesis, and (2) the evidence available does not allow one to establish whether it is on the mark. See also Appendix F in the online supplement, in which we conclude that Mazumder's (2005) estimates of attenuation bias in IGE estimation-as opposed to his IGE estimates-are most likely upward biased, as Chetty et al. (2014) also argued.

4 Chetty et al. (2014) used a measure of positional mobility and persistence, the rank-rank slope, to conduct the bulk of their analyses. Here we are only concerned with their IGE estimates.

5 After excluding the United States, the average IGE among the countries in Corak's (2013:Figure 1) Great Gatsby Curve, which only includes highly advanced economies, is 0.30 . 
6 Chetty et al.'s (2014) 0.34 estimate has been included among the "best current estimates" of the IGE (Fox, Torche, and Waldfogel 2016:535), and some researchers have even interpreted it as a new benchmark for today's United States (Lee and Seshadri [forthcoming]; see also Yum 2015; Daruich and Kozlowski 2016).

7 Or, more precisely, the first such an account that is correct; see note 16 .

8 Mazumder (2016) draws extensively on our own arguments here, which appeared in much less developed form in a working paper that is a predecessor to this article (and which circulated with a different title).

9 The interpretation in terms of equality of opportunity requires additional assumptions. More on this later.

10 The children's conditional distributions become better as parental income increases if, for instance, they are ordered by a relation of first-order stochastic dominance.

11 Often, steeper curves are also interpreted as indicating more inequality of opportunity, which is only correct under assumptions discussed later and only if the inequality in parental income is the same across curves. More on this later.

12 From here on, whenever we refer to the "average slope" of the curve, it should be understood that we are referring to this weighted average.

13 For $Z$ and $W$ any scalar random variables, we use expressions like " $Z \mid w$ " as a shorthand for " $Z \mid W=w . "$

14 Whereas $\ln E(Y \mid x)) \equiv \ln E(Y \mid X=x))$ denotes a constant, $\ln E(Y \mid X))$ denotes a random variable (as in this expression, parental income is not fixed at any particular value). The distribution of this variable is determined by the distribution of $X$, so in both the numerator and denominator, the operator SD is defined with respect to the latter distribution.

15 As Brunori et al. (2013:88-89) aptly put it, "The idea of the ex-ante approach is that inequality of opportunity is the inequality in the value of people's opportunity sets . . . the ex-ante approach to the measurement of inequality of opportunity essentially consists of computing an inequality measure over a counterfactual distribution, where individual advantages are replaced with some valuation of the opportunity set of the type to which the individual belongs." In the most common variant of this approach, that valuation is the mean or expected "advantage" (income, in the case at hand) of those belonging to the type.

16 That is, $\beta_{1}=\frac{S D(\ln G M(Y \mid X))}{S D(\ln X)}$, and $S D(\ln G M(Y \mid X))$ is a measure of inequality of opportunity as long as opportunity sets are indexed by the conditional geometric means of children's income. Lefranc et al. (2009) claimed to have provided a (different) formal account of the relationship between the conventionally estimated IGE (the constant IGE $_{\mathrm{g}}$ ) and inequality of opportunity. That account is flawed because it wrongly assumes that the parameter $\beta_{0}$ in Equation 1 is a structural parameter, allowing for a counterfactual interpretation.

17 As many before them, Brunori et al. (2013:101) claimed that, conceptually, economic persistence and inequality of opportunity "should be very closely related" but did not provide an account of that relationship.

18 In this context, measurement error is defined with respect to the long-run measure. It therefore includes the effects of volatility over time in short-run income.

19 The underlying problem is, of course, that the geometric mean (the unwittingly selected measure of central tendency) is undefined when a variable includes zero in its support.

20 That there is a large share of children with zero short-run (e.g., annual) individual earnings is well known. The same is true for family income: 5.4 and 8.0 percent of 
adults ages 29 to 32 had zero family income in 2011 and 2012, according to data from the Current Population Survey and the American Community Survey, respectively (Chetty et al. 2014:Online Appendix Table 4).

21 In particular, keeping all observations and replacing zeros with a "small amount" does not provide a solution, as estimates vary widely depending on the exact amount that is substituted.

22 After applying the sample selection rules just described, the samples represent between 96.2 percent and 97.7 percent of the relevant populations. For instance, 96.2 percent of children born between 1972 and 1975 who were living in the United States in 1987 and were alive in 2010 are represented by the $2010-9 y$ sample.

23 The problem is generated by children who do not file at all in the corresponding tax year, regardless of whether they file by the filing deadline. Both Chetty et al.'s (2014) and the SOI-M Panel's data do include tax-based income information of late filers.

24 The list of previous estimates of the constant IGE inconsistent with Chetty et al.'s (2014) estimates is substantially longer than they contend. Focusing only on family-income IGE estimates equal to or larger than 0.5 and published before 2014, the list should include Abul Naga (2001, 2002), Chadwick and Solon (2002), Jäntti et al. (2006), Hertz (2005, 2006), and Bratsberg et al. (2007). Two post-2014 survey-data studies based on many years of parental information have reported $\mathrm{IGE}_{g}$ estimates substantially larger than 0.5 (Mazumder 2016; Mitnik 2017b).

25 This evidence is based on left-censored parametric models that assume that the children's income follows the Dagum three-parameter distribution (e.g., Kleiber and Kotz 2003) and in which the income of nonadmins is taken to be below the tax-filing thresholds. We plan to report these results in a separate article. Relying on this type of model for our purposes here was not feasible given our central interest in comparing nonparametric estimates obtained using the SOI-M Panel's and Chetty et al.'s (2014) data.

26 See note 4.

27 Strictly speaking, this only follows in the case of the IGEg. In the case of the IGE follows if we further assume that the imputation bias is relatively small (as this bias is an upward bias). As we mentioned earlier, there is empirical evidence that this is the case.

28 In the case of the constant $\mathrm{IGE}_{\mathrm{e}}$, the difference falls from $0.12(0.46-0.34)$ with the best sample to $0.04(0.38-0.34)$ with the all-biases sample; that is, only one-third of the original difference remains. In the case of the nonparametric $\mathrm{IGE}_{\mathrm{e}}$, the difference falls from $0.12(0.50-0.38)$ to $0.03(0.41-0.38)$; that is, only one-quarter remains.

29 We can proceed in two ways to compute the share of the observed difference accounted for by the four biases. The difference of $0.16(0.50-0.34)$ falls to $0.04(0.38-0.34)$ once the SOI-M all-biases sample is employed to compute the constant $\mathrm{IGE}_{\mathrm{e}}$ or falls to 0.03 (0.41 0.38) once the SOI-M all-biases sample is employed to compute the nonparametric IGE and the estimate of the constant IGE e based on Chetty et al.'s (2014) data is replaced by an estimate of the nonparametric $\mathrm{IGE}_{\mathrm{e}}$ based on the same data. The shares accounted for by the four biases are three-quarters $(1-0.04 / 0.16)$ or more than four-fifths $(1-0.03 / 0.16)$, respectively.

30 In the case of the constant $\mathrm{IGE}_{\mathrm{g}}$, the difference in estimates falls from $0.12(0.46-0.34)$ with the best sample to $0.04(0.34-0.30)$ with the two-year all-biases sample; that is, only one-third of the original difference remains. In the case of the nonparametric $\mathrm{IGE}_{\mathrm{g}}$, the difference falls from $0.14(0.53-0.39)$ to $0.01(0.40-0.39)$; that is, only 7 percent remains.

31 We can proceed in two ways to compute the share of the observed difference accounted for by the four biases. The difference of $0.19(0.53-0.34)$ falls to $0.04(0.34-0.30)$ once 
the SOI-M two-year all-biases sample is employed to compute the constant IGEg or falls to $0.01(0.40-0.39)$ once the SOI-M two-year all-biases sample is employed to compute the lower-bound of the nonparametric $\mathrm{IGE}_{\mathrm{g}}$, and the estimate of the constant $\mathrm{IGE}_{\mathrm{g}}$ based on Chetty et al.'s (2014) data is replaced by an estimate of the nonparametric IGE $\mathrm{g}$ based on the same data. The shares accounted for by the four biases are almost four-fifths (1 $0.04 / 0.19)$ or almost 95 percent $(1-0.01 / 0.19)$, respectively.

32 The difference of $0.40(0.74-0.34)$ falls to $0.04(0.34-030)$ or to $0.01(0.40-0.39)$ depending on the computation method (see note 31 ). The shares accounted for by the four biases are 90 percent $(1-0.04 / 0.40)$ or 97.5 percent $(1-0.01 / 0.40)$, respectively.

33 This set is empty in the case of the nonparametric estimate based on the 2010-9y sample with CPS-based mean imputation for nonadmin children (the SOI-M best sample). It only includes all four biases we have considered in the case of the constant-elasticity estimate based on the 2004-5y sample with $\$ 0$ imputation for nonadmin children (the SOI-M all-biases sample).

34 In the case of the constant $\mathrm{IGE}_{\mathrm{e}}, 0.08 /(0.08+0.01)=0.85$; in the case of the nonparametric IGE $_{\mathrm{e}}, 0.09 /(0.09+0.01)=0.86$.

35 That is, $0.12 /(0.12+0.01)=0.92$.

\section{References}

Abul Naga, Ramses. 2001. “Galtonian Regression of Intergenerational Income Linkages: Biased Procedures, a New Estimator and Mean-Square Error Comparisons." STICERD Distributional Analysis Research Programme Papers 53, London School of Economics.

Abul Naga, Ramses. 2002. "Estimating the Intergenerational Correlation of Incomes: An Errors-in-Variables Framework." Economica 69:69-91. https://doi.org/10.1111/ 1468-0335.00271.

Arneson, Richard. 1989. "Equality of Opportunity for Welfare." Philosophical Studies 56:77-93.

Arneson, Richard. 2011. "Luck Egalitarianism-A Primer." Pp. 24-50 in Responsibility and Distributive Justice, edited by C. Knight and Z. Stemplowska. Oxford, United Kingdom: Oxford University Press. https://doi.org/10.1093/acprof : oso/9780199565801.003. 0002.

Black, Sandra, and Paul Devereux. 2011. "Recent Developments in Intergenerational Mobility." Pp. 1487-541 in Handbook of Labor Economics, Vol. 4b, edited by D. Card and O. Ashenfelter. Amsterdam, Netherlands: Elsevier. https://doi.org/10.1016/s0169-7218(11) 02414-2.

Böhlmark, Anders, and Matthew Lindquist. 2006. "Life-Cycle Variations in the Association between Current and Lifetime Income: Replication and Extension for Sweden." Journal of Labor Economics 24:879-96. https : //doi .org/10.1086/506489.

Bourguignon, François, and Christian Morrisson. 2002. "Inequality among World Citizens: 1820-1992." The American Economic Review 92:727-44. https://doi .org/10.1257/ 00028280260344443.

Bratsberg, Bernt, Knut Røed, Oddbjørn Raaum, Robin Naylor, Markus Jäntti, Tor Eriksson, and Eva Österbacka. 2007. "Nonlinearities in Intergenerational Earnings Mobility. Consequences for Cross-Country Comparisons." The Economic Journal 117:C72-C92. https://doi.org/10.1111/j.1468-0297.2007.02036.x. 
Brunori, Paolo, Franciso Ferreira, and Vito Peragine. 2013. "Inequality of Opportunity, Income Inequality and Economic Mobility: Some International Comparisons." Pp. 85115 in Getting Development Right, edited by E. Paus. New York, NY: Palgrave Macmillan. https://doi.org/10.1057/9781137333117_5.

Chadwick, Laura, and Gary Solon. 2002. "Intergenerational Income Mobility among Daughters." The American Economic Review 92:335-44. https://doi.org/10.1257/ 000282802760015766.

Checchi, Daniele, Vito Peragine, and Laura Serlenga. 2010. "Fair and Unfair Income Inequalities in Europe." Working Paper 174-2010, ECINEQ.

Chetty, Raj, Nathaniel Hendren, Patrick Kline, and Emmanuel Saez. 2014. "Where Is the Land of Opportunity? The Geography of Intergenerational Mobility in the United States." The Quarterly Journal of Economics 129:1553-623. https: //doi .org/10.1093/qje/qju022.

Clark, Gregory. 2014. The Son Also Rises: Surnames and the History of Social Mobility. Princeton, NJ: Princeton University Press. https ://doi .org/10.1086/686098.

Cohen, Gerald Allan. 1989. “On the Currency of Egalitarian Justice.” Ethics 99:906-44.

Corak, Miles. 2006. "Do Poor Children Become Poor Adults? Lessons from a Cross Country Comparison of Generational Earnings Mobility." Pp. 143-88 in Dynamics of Inequality and Poverty (Research on Economic Inequality), Vol. 13, edited by J. Creedy and G. Kalb. West Yorkshire, United Kingdom: Emerald. https://doi.org/10.1016/ s1049-2585(06) 13006-9.

Corak, Miles. 2013. "Income Inequality, Equality of Opportunity, and Intergenerational Mobility." Journal of Economic Perspectives 27:79-102. https://doi .org/10.1257/jep. 27. 3.79 .

Couch, Kenneth, and Dean Lillard. 1998. "Sample Selection Rules and the Intergenerational Correlation of Earnings." Labour Economics 5:313-29. https://doi .org/10.1016/ s0927-5371 (98)00009-8.

Dahl, Molly, and Thomas DeLeire. 2008. "The Association between Children's Earnings and Fathers' Lifetime Earnings: Estimates Using Administrative Data." Discussion Paper 1342-08, University of Wisconsin-Madison Institute for Research on Poverty.

Daruich, Diego, and Julain Kozlowski. 2016. “Explaining Income Inequality and Intergenerational Mobility: The Role of Fertility and Family Transfers." Working Paper 2018-11, Federal Reserve Bank of St. Louis. https ://doi.org/10.20955/wp. 2018.011.

Ferreyra, Francisco, and Jérémie Gignoux. 2011. "The Measurement of Inequality of Opportunity: Theory and an Application to Latin America." Review of Income and Wealth 57:622-57. https://doi.org/10.1111/j.1475-4991.2011.00467.x.

Ferreyra, Francisco, and Vito Peragine. 2016. "Individual Responsibility and Equality of Opportunity." Pp. 747-84 in The Oxford Handbook of Well-Being and Public Policy, edited by M. D. Adler and M. Fleurbaey. Oxford, United Kingdom: Oxford University Press. https://doi.org/10.1093/oxfordhb/9780199325818.013.24.

Fox, Liana, Florencia Torche, and Jane Waldfogel. 2016. "Intergenerational Mobility." Pp. 528-54 in The Oxford Handbook of the Social Science of Poverty, edited by D. Brady and L. Burton. Oxford, United Kingdom: Oxford University Press. https ://doi .org/10.1093/ oxfordhb/9780199914050.013.24.

Gornick, Janet, and Branko Milanovic. 2015. "Income Inequality in the United States in CrossNational Perspective: Redistribution Revisited." Brief 1/2015, Luxembourg Income Study Center Research. 
Haider, Steven, and Gary Solon. 2006. "Life-Cycle Variation in the Association between Current and Lifetime Earnings." American Economic Review 96:1308-20. https://doi. org/10.1257/aer.96.4.1308.

Heckman, James. 2008. "Selection Bias and Self-Selection." Pp. 242-66 in The New Palgrave Dictionary of Economics, 2nd ed., edited by S. Durlauf and L. Blume. New York, NY: Palgrave. https://doi.org/10.1057/9780230226203.3510.

Hertz, Tom. 2005. "Rags, Riches and Race: The Intergenerational Economic Mobility of Black and White Families in the United States." Pp. 165-91 in Unequal Chances. Family Background and Economic Success, edited by S. Bowles, H. Gintis, and M. Osborne Groves. Princeton, NJ: Princeton University Press. https: //doi .org/10. 1515/9781400835492. 165.

Hertz, Tom. 2006. "Understanding Mobility in America." Center for American Progress. https://www. americanprogress.org/wp-content/uploads/kf/hertz_ mobility_analysis.pdf.

Jäntti, Markus, Bernt Bratsberg, Knut Røed, Oddbjørn Raaum, Robin Naylor, Eva Österbacka, Anders Björklund, and Tor Eriksson. 2006. "American Exceptionalism in a New Light: A Comparison of Intergenerational Earnings Mobility in the Nordic Countries, the United Kingdom and the United States." Discussion Paper 1938, IZA.

Kleiber, Christian, and Samuel Kotz. 2003. Statistical Size Distributions in Economics and Actuarial Sciences. Hoboken, NJ: Wiley.

Lee, Sang Yoon, and Ananth Seshadri. Forthcoming. "On the Intergenerational Transmission of Economic Status." Journal of Political Economy.

Lefranc, Arnaud, Nicolas Pistolesi, and Alain Trannoy. 2009. “The Link between Inequality of Opportunity for Income Acquisition and Income Inequality: The French Example, 1977-1993." Retrieved January 5, 2019 (https : //www.tse-fr.eu/sites/default/ files/medias/TSE/ResearchGroups/PublicEconomics/pistolesi.pdf).

Mazumder, Bhashkar. 2001. “The Mis-Measurement of Permanent Earnings: New Evidence from Social Security Earnings Data." Working Paper 2001-24, Federal Reserve Bank of Chicago. https://doi.org/10.2139/ssrn.296131.

Mazumder, Bhashkar. 2005. "Fortunate Sons: New Estimates of Intergenerational Mobility in the United States Using Social Security Earnings Data." The Review of Economics and Statistics 87:235-55. https://doi .org/10.1162/0034653053970249.

Mazumder, Bhashkar. 2016. "Estimating the Intergenerational Elasticity and Rank Association in the United States: Overcoming the Current Limitation of Tax Data." Pp. 83-130 in Inequality: Causes and Consequences, edited by L. Cappellari, S. Polacheck, and K. Tatsiramos. Bingley, United Kingdom: Emerald Group Publishing. https: //doi.org/10.1108/s0147-912120160000043012.

Mitnik, Pablo. 2017a. "Estimating the Intergenerational Elasticity of Expected Income with Short-Run Income Measures: A Generalized Error-in-Variables Model." Working Paper, Stanford Center on Poverty and Inequality.

Mitnik, Pablo. 2017b. "Intergenerational Income Elasticities, Instrumental Variable Estimation, and Bracketing Strategies." Working Paper, Stanford Center on Poverty and Inequality.

Mitnik, Pablo. 2017c. “'Person-Weighted' versus 'Dollar-Weighted': A Flawed Characterization of Two Intergenerational Income Elasticities." Working Paper, Stanford Center on Poverty and Inequality. 
Mitnik, Pablo, and David Grusky. 2017. “The Intergenerational Elasticity of What? The Case for Redefining the Workhorse Measure of Economic Mobility." Working Paper, Stanford Center on Poverty and Inequality.

Mitnik, Pablo, Victoria Bryant, Michael Weber, and David Grusky. 2015. “New Estimates of Intergenerational Mobility Using Administrative Data." Statistics of Income Working Paper, Internal Revenue Service.

Mitnik, Pablo, Victoria Bryant, Michael Weber, and David Grusky. 2018. "A Very Uneven Playing Field: Economic Mobility in the United States." Working Paper, Stanford Center on Poverty and Inequality.

Mulligan, Casey. 1997. Parental Priorities and Economic Inequality. Chicago, IL: University of Chicago Press.

Nybom, Martin, and Jan Stuhler. 2016. "Heterogeneous Income Profiles and Life-Cycle Bias in Intergenerational Mobility Estimation." The Journal of Human Resources 15:239-68. https://doi.org/10.3368/jhr.51.1.239.

Ramos, Xavier, and Dirk Van de gaer. 2015. “Approaches to Inequality of Opportunity: Principles, Measures, and Evidence." Journal of Economic Surveys 30:855-83. https: //doi.org/10.1111/joes.12121.

Roemer, John. 1998. Equality of Opportunity. Cambridge, MA: Harvard University Press. https://doi.org/10.1257/jel.20151206.

Roemer, John, and Alain Trannoy. 2016. "Equality of Opportunity: Theory and Measurement." Journal of Economic Literature 54:1288-332.

Santos Silva, João M. C., and Silvana Tenreyro. 2006. “The Log of Gravity.” The Review of Economics and Statistics 88:641-58.

Schoeni, Robert, and Emily Wiemers. 2015. "The Implications of Selective Attrition for Estimates of Intergenerational Elasticity of Family income." Journal of Economic Inequality 13:351-72. https://doi .org/10.1007/s10888-015-9297-z.

Shorrocks, Anthony. 2013. “Decomposition Procedures for Distributional Analysis: A Unified Framework Based on the Shapley Value." The Journal of Economic Inequality 11:99-126. https://doi .org/10.1007/s10888-011-9214-z.

Solon, Gary. 1992. "Intergenerational Income Mobility in the United States." American Economic Review 82:393-408.

Solon, Gary. 1999. "Intergenerational Mobility in the Labor Market." Pp. 1761-800 in Handbook of Labor Economics, Vol. 3A, edited by O. C. Ashenfelter and D. Card. Amsterdam, Netherlands: Elsevier. https://doi .org/10.1016/s1573-4463(99)03010-2.

Solon, Gary. 2008. “Intergenerational Income Mobility." Pp. 3128-31 in The New Palgrave Dictionary of Economics, 2nd ed., edited by S. Durlauf and L. Blume. Basingstoke, United Kingdom: Palgrave Macmillan. https ://doi .org/10.1057/978-1-349-95121-5_2081-1.

Yum, Minchul. 2015. "Parental Time Investment and Human Capital Formation: A Quantitative Analysis of Intergenerational Mobility." Paper presented at the Annual Meeting of the Society for Economic Dynamics, June 25-27, Warsaw, Poland. 
Acknowledgments: The first author gratefully acknowledges research support from the Russell Sage Foundation and the Pew Charitable Trusts. The editors provided valuable feedback on an earlier version of the article. The opinions expressed in this article are solely those of the authors and do not represent the opinions of the Internal Revenue Service or the Stanford Center on Poverty and Inequality.

Pablo A. Mitnik: Center on Poverty and Inequality, Stanford University. E-mail: pmitnik@stanford.edu.

Victoria Bryant: Statistics of Income Division, Internal Revenue Service. E-mail: victoria.1.bryant@irs.gov.

Michael Weber: Statistics of Income Division, Internal Revenue Service.

E-mail: michael.e.weber@irs.gov. 